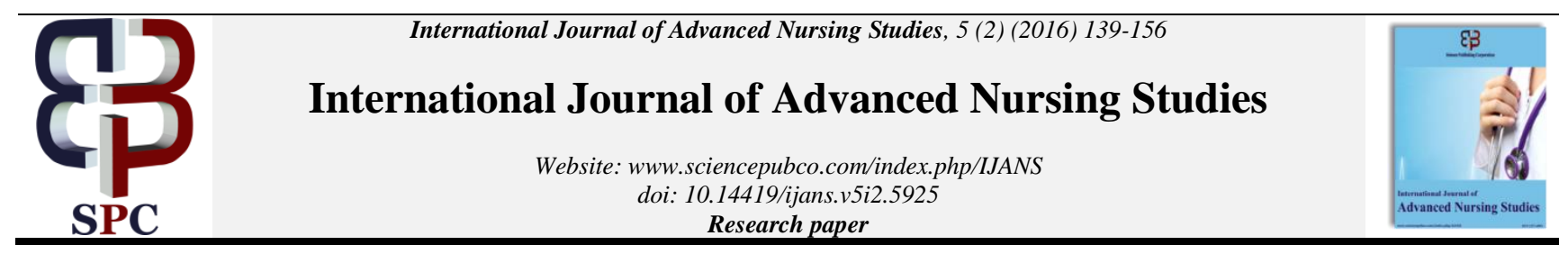

\title{
An assessment of knowledge and factors that exposed young female student nurses to hiv infection at the university of Namibia, oshakati campus
}

\author{
Selma Ingandipewa Uushona *, Lusia N. Pinehas \\ Faculty of Health Sciences, School of Nursing and Public Health, University of Namibia: Namibia \\ *Corresponding author E-mail: suushona@unam.na
}

\begin{abstract}
Background: This study presents an assessment of knowledge and an investigation of specific factors that expose young female student nurses to HIV and AIDS at university of Namibia, Oshakati Campus. The concern over to what young female student nurses are able to control various issues of their sexual lives is critical question for health promotion and the prevention of further HIV infection. Student nurses are believed to have adequate information about HIV and AIDS compared to other young people in the communities.

Aim: To assess HIV and AIDS knowledge levels and investigates factors that make young female nurses vulnerable to HIV infection at UNAM, Oshakati Campus

Method: A mixed-method approach was employed to collect the necessary data, a combination of qualitative and quantitative methodology. Qualitative data was collected through a self-administered questionnaire whereas qualitative data was gathered by means of focus group discussions. Quantitative data was analyzed using the Statistical Package for Social Sciences (SPSS) 18, and results from the focus group discussions were grouped into themes and subthemes and analyzed using thematic analysis. Random sampling with replacement technique namely, the fishbowl technique was used to select respondent and participants. This ensures equal and independent chance of being selected each time.

Results: Most respondents indicated to have adequate knowledge about HIV and AIDS and had positive attitude necessary to effect behavioral change and implementation of prevention and care strategies. Most respondents were aware of their risk factors and aspects that increased individual vulnerability to HIV and AIDS. While the knowledge and attitude were identified as adequate, the practices of the respondents did not explicit indicate adequate level of responsible behavior among the young female student nurses in the face of HIV and AIDS.

Conclusion: Student nurses identified HIV and AIDS as a problem of "others" and continue to report that infection would be an accidental exposure as a result of their profession or perceived powerless over sexual matters and income inequalities. Prevention remains a challenge in planning programs needed to address risky sexual behavior among students due to structural, social, socio-economic dynamics, individual circumstances, gender and biological vulnerability.
\end{abstract}

Keywords: Assessment; Factors; Expose; Young; Female; Hiv Infection; Knowledge; Student Nurse.

\section{Introduction}

The concern over to what extent young female student nurses are able to control various issues of their sexual lives is a critical question for health promotion and the prevention of further HIV infections. The majority of young female student nurses at the University of Namibia (UNAM), Oshakati campus are from rural areas and their entry to a tertiary institution is a challenge in itself and the pressure of a new environment may add stress to their already pressed situations. The transit period leaves them uncertain and unable to cope with the demands of the new environment. Most of the young students are from poor family backgrounds and it is challenging for them to resist the temptations of cross generational sexual relationships for monetary and other survival gains. Moreover, joining UNAM ushers them to freedom from the possibly restricted lifestyle under the supervision of their parents and guardians. This in effect makes them vulnerable to various risky sexual behaviors. Some of the possible reasons that might expose the young women to risky sexual behaviors include the desire to meet the cost of living and what is considered to be a decent lifestyle. There is equally a danger of alcohol and substance abuse, boredom and peer pressure that contribute to the further spread of HIV.

There is no direct data source which provides the extent or prevalence rate of HIV among female student nurses at UNAM Oshakati campus. The only available means to establish the prevalence rate is by using the 2008 Ministry of Health and Social Services HIV sentinel survey results. HIV prevalence among pregnant women was at $22.4 \%$ at Oshakati Intermediate Hospital. Oshakati is the town where the campus is located. A $10.6 \%$ prevalence rate was reported among pregnant women aged 15-24 (MoHSS Report of the 2008 national HIV sentinel survey). Using these statistics to estimate the prevalence of HIV infection among female nursing students at UNAM can be an exaggeration although the incidence of unplanned pregnancies among female nursing students is high and a major concern to the authority of the University. This concern was the main motivation for this study.

Between 2007 and 2009 twenty cases of unplanned pregnancies were reported of the 230 female students at the Oshakati campus 
(University of Namibia, record on maternity leave and absence from theoretical sessions for 2007-2009). Pregnancies at campus highly suggest that students engage in unprotected sex which increases the possibility of exposure to HIV infection.

\section{Methods}

\subsection{Research designs and methods}

The research was conducted systematically in order to generate new knowledge and also to refine existing knowledge and to align it with the knowledge needed to pursue appropriate preventive measures of HIV and AIDS among female nursing students. The researcher used mixed method approaches, qualitative and quantitative designs with the reason of obtaining adequate information (De Vos et al. 2005). The research tools used for data collection were a questionnaire and focus groups. This study was conducted with the purpose to give descriptive information pertaining to knowledge of factors that expose young female nursing students to HIV and AIDS at UNAM Oshakati campus. The research involved focus group discussions as a qualitative methodology.

The target population was all full-time female student nurses under 25 years at the University of Namibia, Oshakati Campus. The rationale for focusing on this age group was because youth are generally believed to be a high risk group for contracting HIV and AIDS in Namibia (MoHSS 2008). The research included all young female students, aged between 16-24 years, unmarried, and who were accommodated in hospital nurses homes, living with parents/guardians and/or renting private accommodation facilities. The Oshakati campus has a total of 372 full-time nursing students out of which 51 students are males and 91 females aged 25 years and above, excluded from the study. There are 230 young female student nurses who are below 25 years. As it supported in literature, a population is the entire group of person or objects that is of interest to researcher (Brink 2006). The researcher selected 115 female student nurses ( 50 percent of the total) to participate in the study and 95 student nurses were selected to complete the questionnaire. The researcher carried out two focus group discussions with 20 students for one hour each. The participants in focus group discussions did not participate in completing the questionnaires.

The researcher used random sampling with a replacement technique namely, the fishbowl technique. The researcher wrote names from the sampling frame on a separate paper, and placed them into a container, then drew a name, noted and placed the name back into the container. The researcher selected more than the required number of names from the sample population in case any selected participant declined to take part in the study. Replacing each name after each selection ensured that each participant had an equal and independent chance of being selected each time (Cresswell 2003). The researcher conducted the survey (using questionnaires) and the focus group discussions on the same day. This offered equal opportunity for the use of both quantitative and qualitative methods and facilitated the integration of data collection and clarification in a timely manner.

The participants included are those who agreed to meet in the class-rooms for one hour, between $13 \mathrm{~h} 00$ and $14 \mathrm{~h} 00$ on normal work days, except Wednesdays due to limited time spent on classroom activities, as students are on a day release shift system. The permission to conduct the survey during lunch time was obtained from the Head of Department of Nursing Science. The researcher also sought consent of the lecturers who were accountable for last class sessions before lunch to assist in the administration of the questionnaires to participants.

\subsection{Data collection}

A pilot study was conducted in August 2010 at Onandjokwe Health Training Centre with pupil enrolled nurses. With permission from the head and the consent of pupil nurses, draft data col- lection tools were administered to 20 pupils for the pilot. A pilot study is a prerequisite for the successful execution and implementation of a research project (De Vos et al. 2005; Burns and Grove 2005).

For data collection the researcher used two data collection methods namely a questionnaire and focus group discussions. The two methods were used to collect data from female nursing students. The two data collection methods are further discussed in detail and how they were applied during the process of data collection.

Data for the survey was collected by means of questionnaires, developed by the researcher. The researcher used structured questions so as to capture relevant data for the purpose of the study. The participants used a paper-pencil format but some participants completed with a black ink pen and marked with " $\mathrm{X}$ " their desired responses (Fink 2003). The first part of the questionnaire consisted of closed ended questions, with categories such as "true" or "false"; "yes" or "no", The second part of questions used a Likert scale rating, with statements and summated declarative statements on which the respondents were required to provide their opinions using a 5 level scale system from strongly agree to strongly disagree (Brink 2006). The rationale and objective the questionnaire was to measure and or test the feelings, attitudes and to obtain rich in depth information, facts and opinions about HIV knowledge and identify factors which are critical to HIV vulnerability among young female students who are informed and familiar with the subject matter. The questionnaire was prepared in the English language and there was no need to translate since the respondents were familiar with the language in use. The questionnaire was physically distributed to the respondents by the researcher.

Focus group discussions were carried out with twenty (20) female student nurses who did not participate in the completion of the questionnaire. The participants were divided into two groups, ten participants each, one with students from the first and second year and the other ten participants from the third and fourth year. The aim for having 10 participants per group was to allow everyone to participate and for the researcher to elicit a range of responses. Further the researcher was able to keep the participants focused and obtained quality information and adequate responses. The focus group discussions were held for at least one hour per group. It was cost effective for the researcher in terms of time and funds. Although this was an open discussion, the researcher had prepared some questions that were used to lead the discussion without limiting the amount of information obtained from the participants. All questions for focus group discussions were in an open-ended format, which enabled participants to provide and motivate their opinions. The open ended questions assisted participants to respond and answer freely in their own words and styles. It was noticed that the participants were confident, comfortable and secure to express their views in groups

\subsection{Data analysis}

Data captured from the questionnaire was analyzed using the statistical package for social sciences (SPSS). Results were presented in frequency tables, bar charts and pie charts.

Data collected from focus group discussions was analyzed using thematic analysis. By this the researcher tape recorded and transcribed conversations with participants quoted and paraphrased what the participants said and analyzed identifiable themes

\subsection{Ethical considerations}

Ethical clearance for the study was granted by the University of Stellenbosch Ethical Research Committee, South Africa. The permission for conducting the study was obtained from the Ministry of Health and Social Services and the Director of UNAM, Oshakati campus. Anonymity was ensured and participants did not provide their names and any other personal particulars. The study results were linked to questionnaire information by way of codenumbers. The participants' rights were respected and their informed consent was obtained before they participated in the re- 
search. Their privacy was maintained and confidentiality was ensured. Participation in the study was voluntary, and participants were allowed if they so wished to withdraw from the study at any time. The researcher explained the purpose of the study to promote better understanding of the nature of the research, its impact on the participants and the procedure to be followed in the study for participants to have clear view on what to anticipate in the research. The participants were allowed and encouraged to ask questions.

\section{Results}

\subsection{Demographic data of the respondents}

Twenty female student nurses aged 16-24 participated in two focus group discussions of ten members each. One group was composed of students from year 1 and 2 while the second group consisted of students from year 3 and 4. All focus group discussions were held at the University of Namibia, Oshakati Campus - faculty of Health Sciences.

The researcher moderated the proceedings of the focus group discussions, presented questions, made clarifications where necessary and recorded responses from respondents. All participants were familiar with the researcher who works as a lecturer at the university. Although this commonness existed, group discussions were benchmarked by standard group rules including confidentiality, respect for each other, listening and openness.

Ninety five questionnaires were administered to female nursing students at UNAM Oshakati Campus. The questionnaire return rate was $100 \%$. All the participants were female full time nursing students at the University of Namibia, Oshakati Campus. The questionnaire had 10 sections that sought out for demographic data, knowledge about HIV and AIDS, risk perceptions, possible barriers to access for health care services, HIV prevention and factors that expose young female students to HIV.

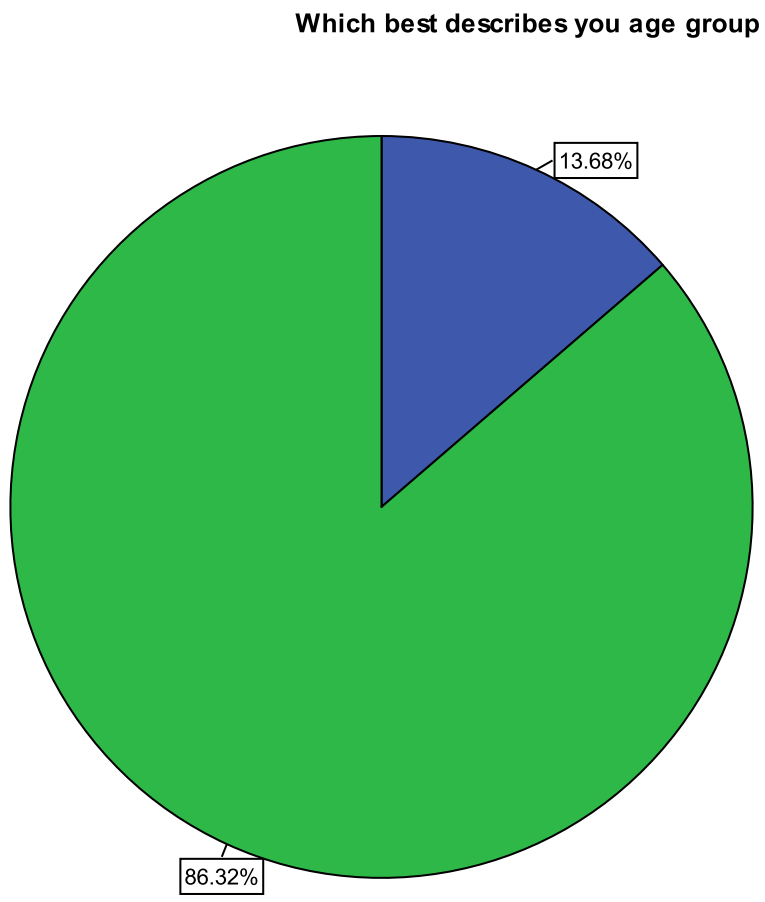

Fig. 1: Age Distribution of Respondents.

The majority of the respondents in this study $(86 \%)$ were adult students aged 20-24. In Namibia the HIV and AIDS epidemic is felt hardest among the 15-49 age with over (20\%) prevalence rate among this age group. The smallest age group (16-19) of respondents $(14 \%)$ is also among the high risk age bracket. Overall therefore, the respondents are from the age bracket considered to be at high risk of HIV infection in Namibia. Over $90 \%$ of the respondents indicted to have originally come from village homes with approximately $10 \%$ stating to be originally from town settings. However, at the University, the respondents indicated to be staying in different settings with the majority $(57 \%)$ staying at the nurses' home, $22 \%$ in rented houses or flats and $20 \%$ still staying with parents at home, from where they travel to the university for lectures. Places of origin and residence were later identified in this study as very influential in determining the level of vulnerability reported by the respondents.

\subsection{Knowledge about HIV and AIDS}

Respondents were tested on various aspects that determine knowledge about HIV and AIDS including transmission, prevention, care, and access to HIV and AIDS services. Overall respondents indicated to be adequately knowledgeable about HIV and AIDS rating between $63 \%-89 \%$ of the respondents being aware about the transmission, prevention, care and access to services. However, in some aspects results of significance were recorded. In sub-Saharan Africa heterosexual contact accounts for over $70 \%$ of all HIV infections that occur in the region, a figure that is higher in the SADC sub-region and for Namibia in particular heterosexual contact accounts for approximately $89 \%$ of all new infections. In this study, $20 \%$ of the respondents indicated that heterosexual contact did not transmit HIV at over 70\% in sub-Saharan Africa as shown in figure 2 below.

On prevention, over $95 \%$ indicated that abstinence from sexual intercourse was one effective method of preventing HIV transmission. However during the focus group discussion, participants challenged abstinence indicating that while it was effective it lacked boundaries and especially that the abstinence does not indicate particularly until when one should abstain.

Further, respondents indicated that significantly that it is impossible to abstain once a person has been sexually active. Figure 4 below indicates that over $48 \%$ of the respondents believed they could not abstain from sex once they were active even when they considered abstinence as an effective method of HIV prevention. See figure 3 above. 


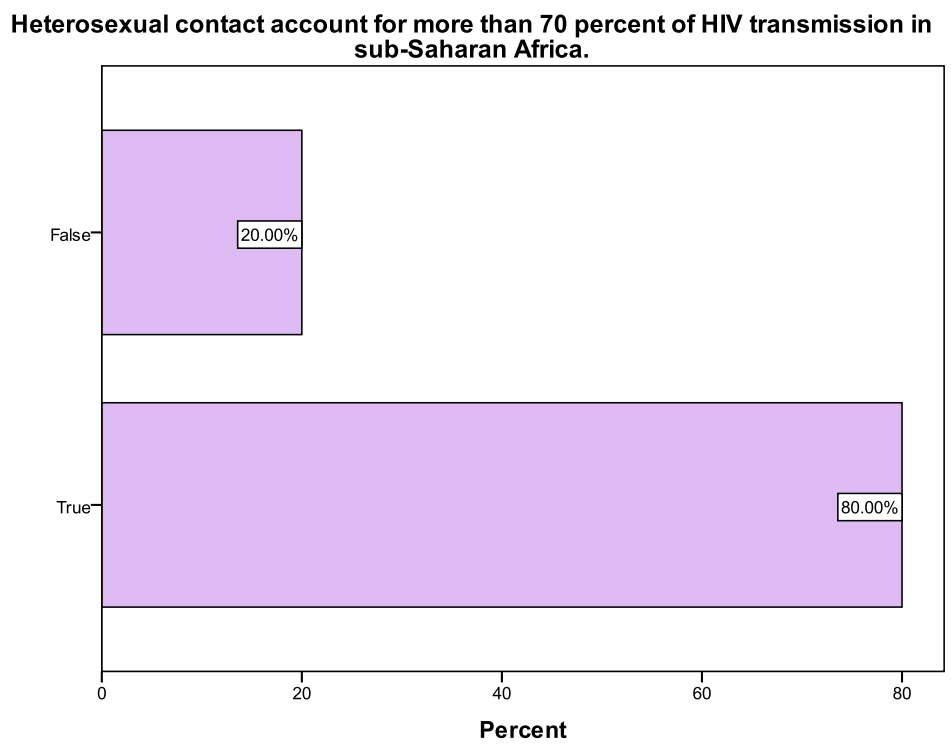

Fig. 2: Heterosexual Contact Transmits HIV at More than $70 \%$ in Sub-Saharan Africa.

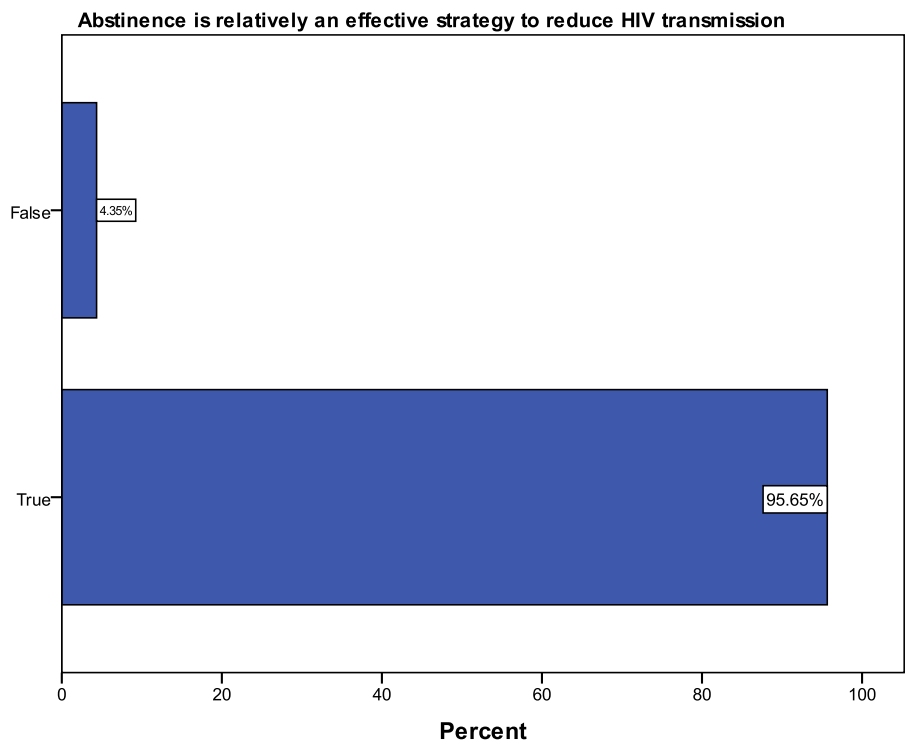

Fig. 3: Abstinence Effective in Preventing HIV Transmission.

It is impossible for the youth to refrain from sexual activities once one becomes sexually active

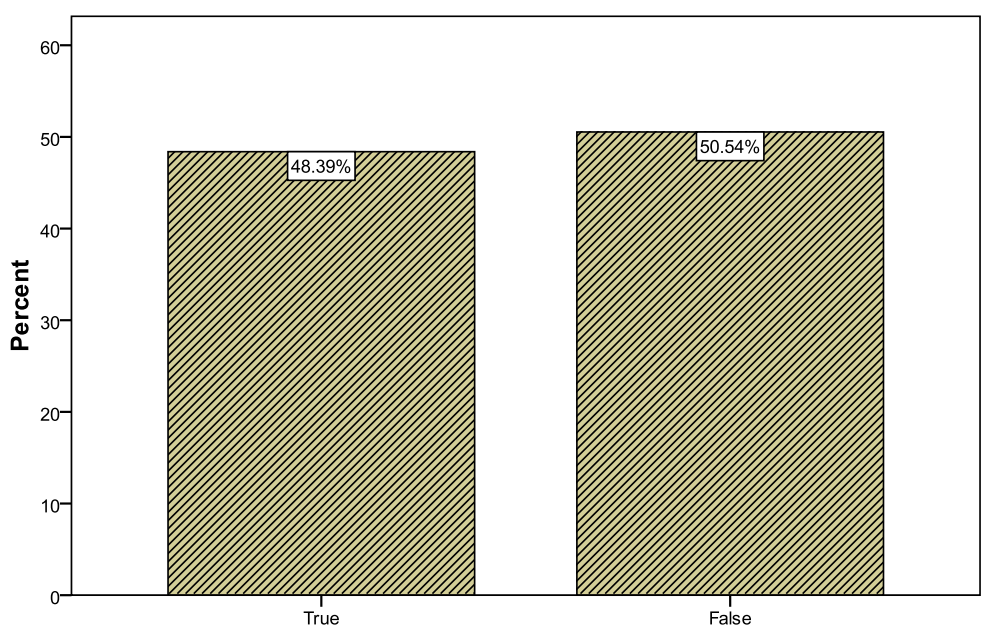

Fig. 4: It Is Possible to Abstain If Someone has Been Sexually Active Before. 


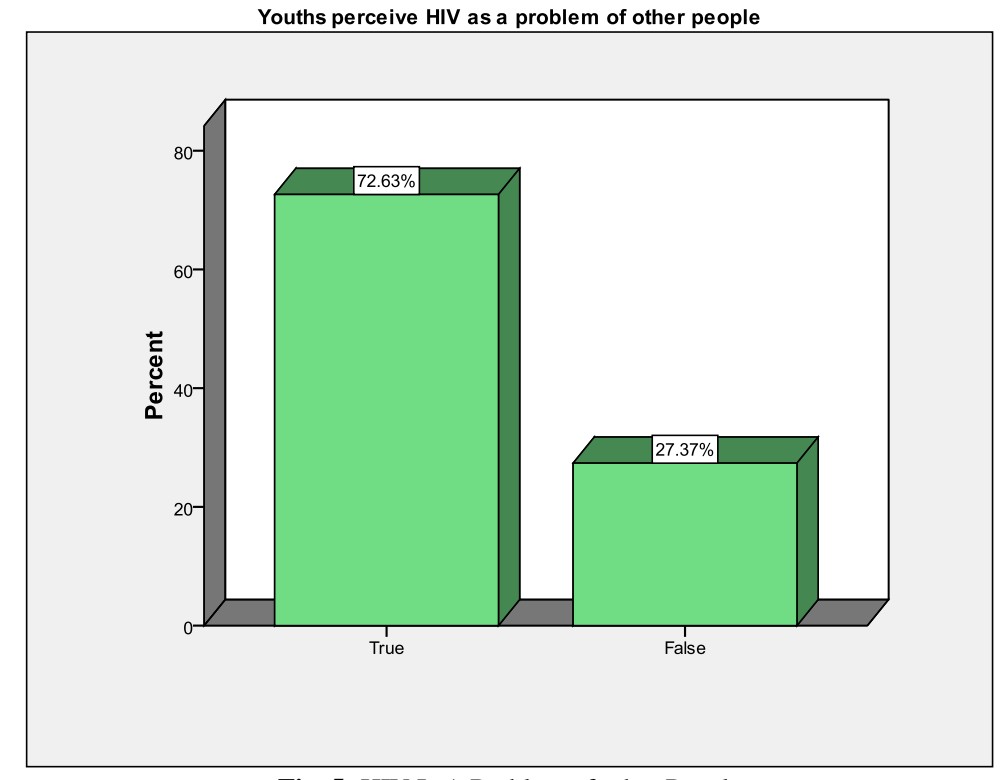

Fig. 5: HIV Is A Problem of other People.

Despite the high level of HIV and AIDS knowledge and awareness, the majority of respondents perceived HIV and AIDS as a problem of others. The student nurses generally viewed their profession as exposing them to greater risk effectively linking the blame to the patients who could be HIV infected and under their care. Accidents with needles and other workplace equipment do occur, but no cases of infection have been officially reported or confirmed in training facilities for nurses, and practice areas such as wards in Oshakati Hospital.

\subsection{Risky behaviors}

Overall, respondents indicated a high degree of awareness of risky behavior ranging from accepting gifts in exchange for sex to multiple sexual partners. Over $94 \%$ of the respondents perceived sex in exchange for gifts as risky. Generally young girls in Namibia accept various favors including gifts from men usually older than them and accept to have sex with them as a means to appreciate the gifts they receive. Further over $86 \%$ of the respondents agreed that transactional sex constituted risky behavior. As opposed to sex in exchange for gifts, transactional sex involves a deliberate choice to offer sexual pleasures in exchange for money or monetary equivalents.

Similarly, findings reveal that over $96 . \%$ perceived that multiple sexual partners constituted risky behavior. This finding is in agreement with the general view that increase in sexual partners is associated with HIV infection. The risk is believed to be greater with especially multiple concurrent sexual partners mainly because it is difficult to ensure faithfulness among the different partners and safer practices can be jeopardized by other factors and should one of the many partners be infected, the rest of the people sexually connected are at risk. The current prevention campaign initiated by USAID in Namibia dubbed "who are you connected to?" is essentially as a result of the recognition that the phenomenon of multiple concurrent sexual partners is potentially a high risk factor among the sexually active population in Namibia.

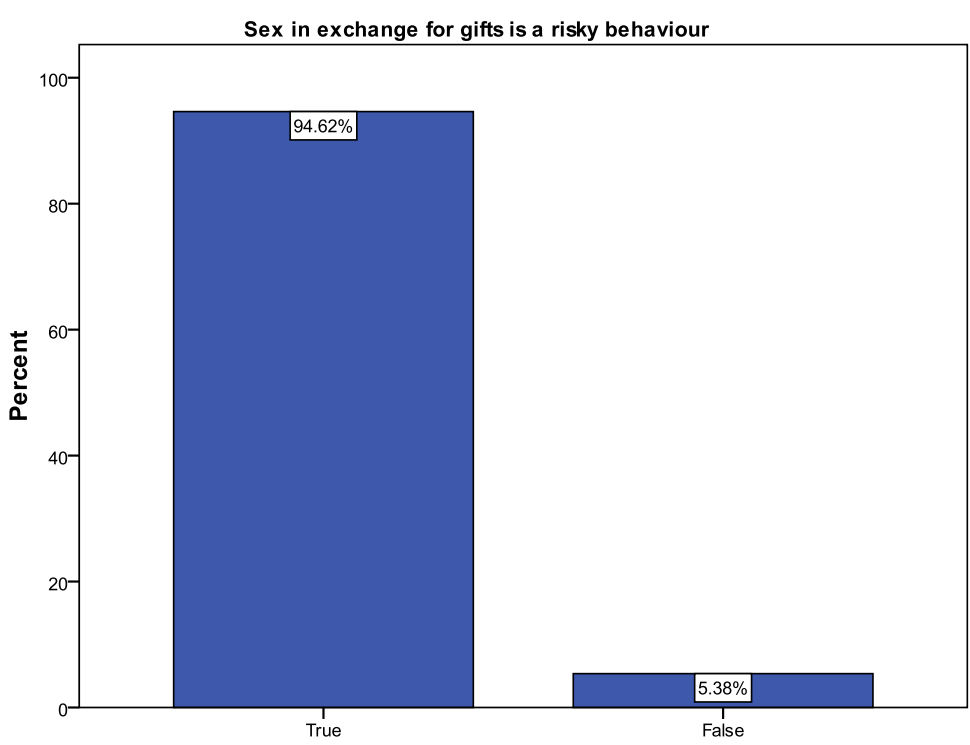

Fig. 6: Sex in Exchange for Gifts Is Risky. 


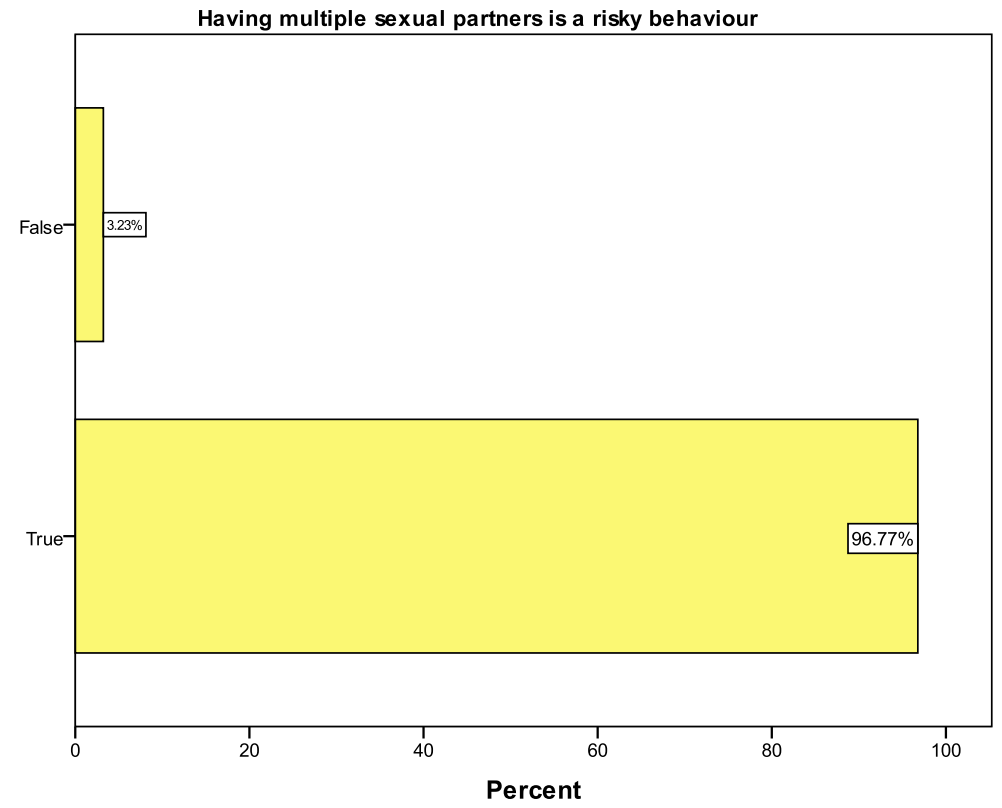

Fig. 7: Multiple Sexual Partners are A Risky Behavior.

Other risky behavior identified included engaging in sexual intercourse during the menstruation period with an HIV positive woman with $88.2 \%$ of the respondents considering it risky. Excessive use of alcohol and substances, dry sex, rape and coerced sex, were viewed as risky behavior with each receiving over $90 \%$ of the responses in the affirmative.

Overall therefore, it can safely be stated that essentially most respondents had adequate knowledge of risky behavior and are able to discern effectively acts that can increase individual exposure to HIV and AIDS which in turn can be used to influence actions that may lead to the reduction in the spread of HIV.

\subsection{Barriers to access of health care}

Effective management of HIV and AIDS requires availability and open access to health care services for both infected and affected.
To access testing services is important as a means to initiate prevention and care services for tested persons whatever the result of the test may be. Respondents were in this study asked if they considered some barriers that could prevent them from accessing health care services in the face of HIV and AIDS. The barriers identified included bad attitudes of health workers, stigma, women being shy and a lack of supplies especially the condom.

$70.5 \%$ of the respondents asserted that bad attitudes of health care workers are a major barrier to the access of HIV and AIDS health care services. This finding is of particular significance since the respondents are themselves nurses in the making and yet reveal strongly that bad attitudes of care providers prevent them from using available health care services.

Bad attitude of Health workers is a barrier to accessing health care services
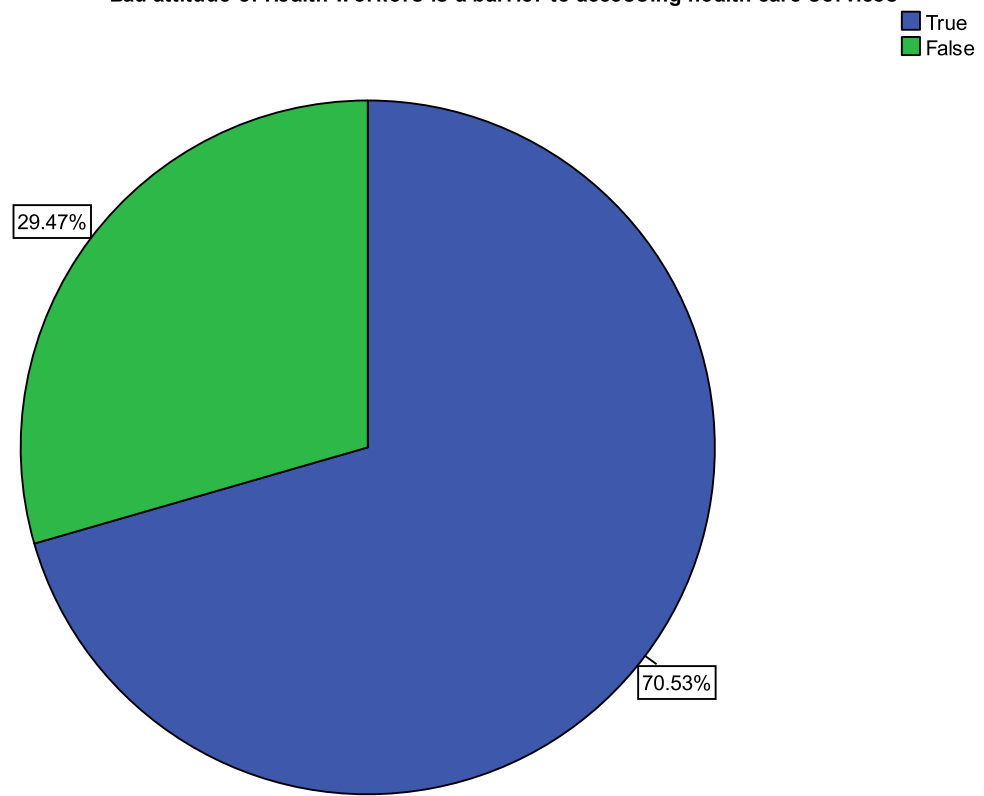

Fig. 8: Bad Attitude of Health Care Providers as a Barrier to Access of HIV and AIDS Services. 


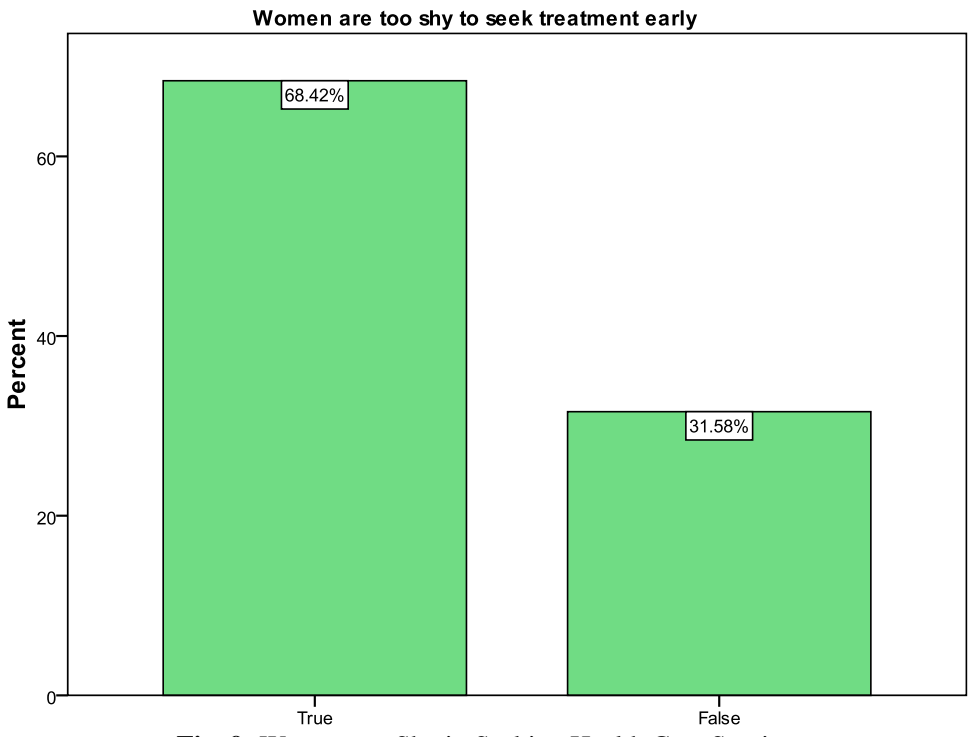

Fig. 9: Women are Shy in Seeking Health Care Services.

In addition, $68 \%$ of the respondents indicated that women are shy in seeking health care services and that is a major barrier. This finding is again of greater significance considering that the respondents are women and particularly university students who constitute the elite of the communities they live in.

\subsection{Gender inequality and violence}

The researcher intended to assess knowledge and perceptions of the respondents on the subject of gender inequality and violence as causative factors in heightening the levels of vulnerability of young female students to HIV and AIDS. Assessment was done on the perception of HIV and AIDS as a universal problem, decision making on the timing and conditions under which sex occurs by young women, income inequalities, sexual harassment, early child bearing and cross-generational sex.

As earlier revealed, over $72 \%$ of the respondents perceived HIV and AIDS as a problem of other people, not the youth. Looking at the variables in this section reveals further that respondents understood to be at risk as a result of several other factors. Over $90 \%$ (See figure 12 below) of the respondents indicated that young women lacked the power to decide on the timing of sex. This finding is in agreement with the previous revelation as young women continue to believe that their vulnerability is circumstantial and controlled by other factors, in this case, the men who are perceived to have control over the timing of sex.

Further, approximately $70 \%$ of the respondents believed that young women have no ability to make correct decisions on the conditions under which sex should occur. Again, a perception that someone else particularly connoting the man controls even the conditions under which sex occurs and that the female counterpart is on the receiving end which compromises the safety of young women in the face of HIV and AIDS.

Findings from the study reveal that young women up to $91.6 \%$ exchange sex for economic stability (See figure 13 below). Female students revealed that economic needs which included housing, transport, tuition fees and food exposed many young students to the risk of exposure to HIV as they sought able men who meet the costs of these needs and reward them with sex.

The most common relationship where women exchange sex for economic stability involves usually older men who could be mar- ried with families. $83 \%$ of the respondents indicated that women involved in cross-generational sexual relationships have little to no bargaining power over the functioning, safety and negotiation of sexual matters as the men are not only older but hold the economic lifeline of the young women.

The above often results in increased vulnerability to sexual abuse and harassment for many young women. Results from this study (see figure 14 below) reveal that almost all respondents are aware that sexual harassment increases their risk to HIV infection. The fear of and exposure to harassment is exacerbated by identified powerlessness in decision making by young women over sexual matters and income inequalities that result in women using sex as a tool to please men and sustain relationships even if they are risky for the purpose of accessing and meeting their basic needs.

Increased vulnerability and compromised or lost control over young women's life easily results in early child bearing. Over $75 \%$ of the respondents indicated that early child bearing restricts young women from studying further. It is possible therefore that a cycle of marginalization becomes difficult to break as unqualified women who are made mothers at an early age cannot access gainful employment yet they can't study further to gain employable skills.

\subsection{Attitudes towards condom use}

Correct and consistent condom use as a means of prevention of HIV transmission is inextricably linked to individual attitudes, perceptions and attributes towards the condom. The researcher intended through this section to investigate individual attitudes of the respondents towards condoms and condom use. Five different variables were used to asses respondent attitudes, which included the idea that condom use increased promiscuity, that condoms are for prostitutes, condoms are a sign of unfaithfulness and a lack of love, and that condoms caused frustration in relationships. To gain a deeper insight on attitudes of individual respondents, data in this section was analyzed by age group to gauge how the different age groups perceived condoms and condom use. 
Young women lack the power to decide on the timing of sex

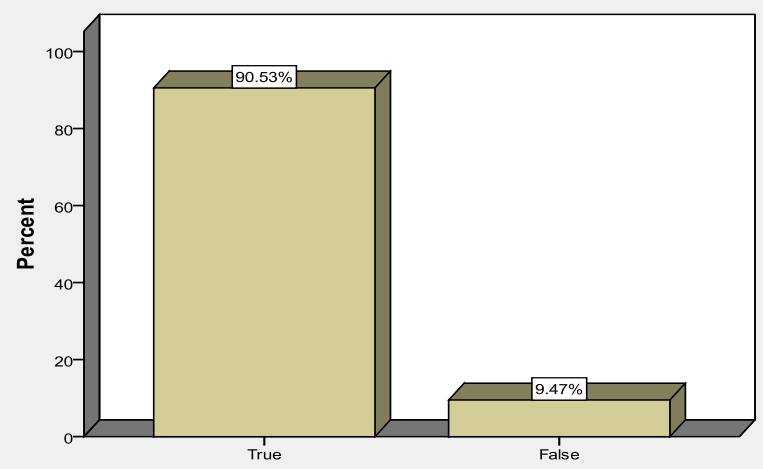

Fig. 10: Young Women Lack the Power to Decide on the Timing of Sex.

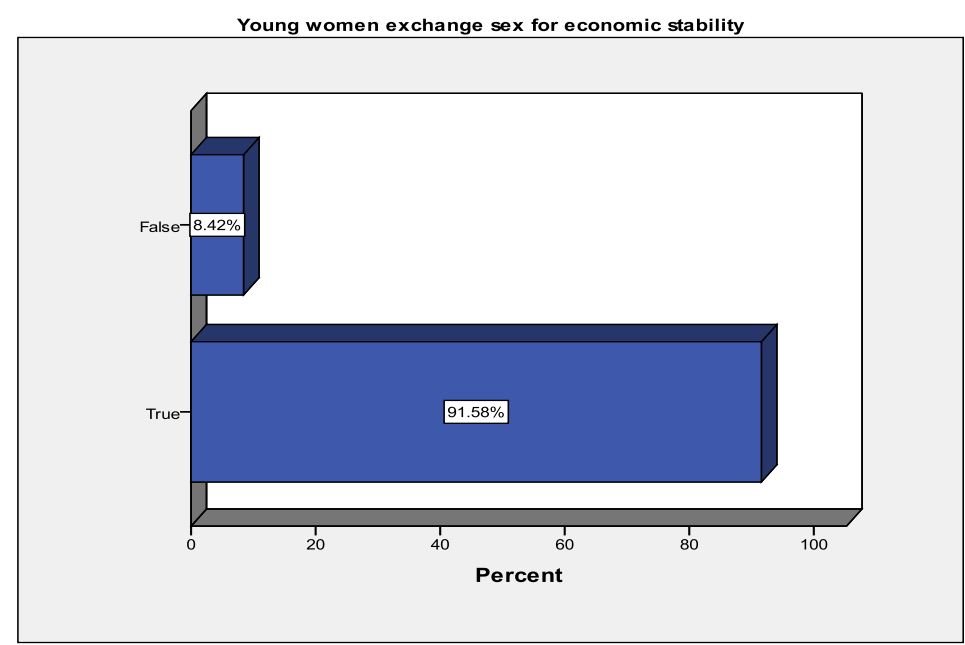

Fig. 11: Young Women Exchange Sex for Economic Stability.

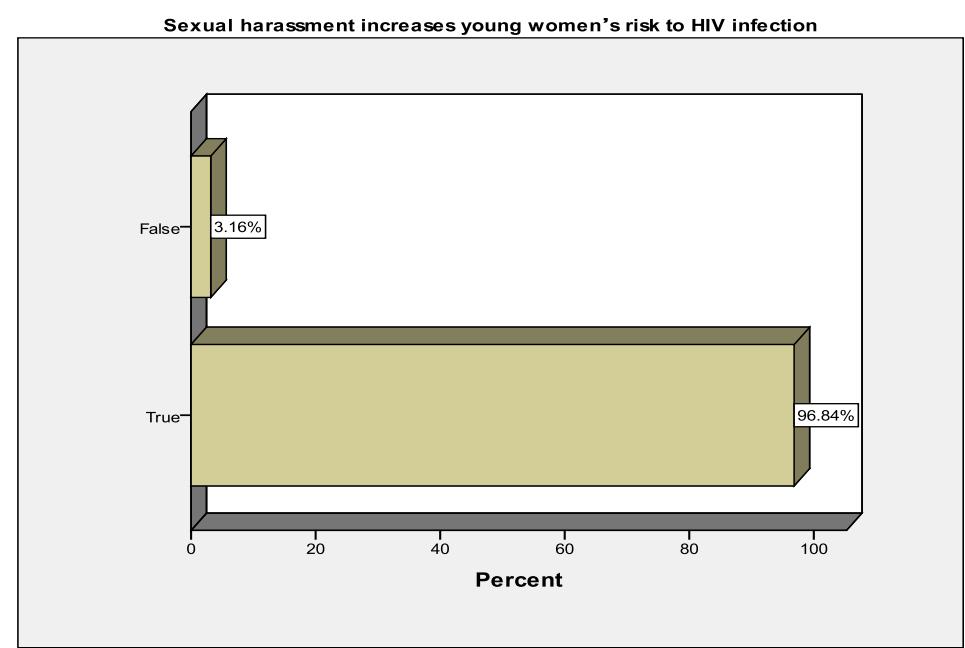

Fig. 12: Sexual Harassment Increases Young Women's Risk to HIV Infection. 


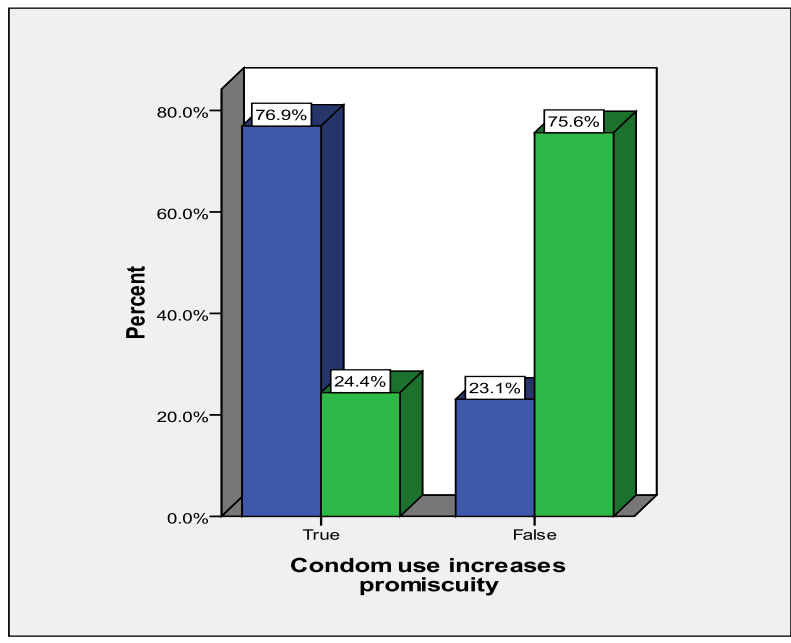

Age group

$16-19$ Years
$\square 20-24$ Years

Figure 13: Condom Use Increases Promiscuity.

On the contrary however, figure 18 above reveals that over $76 \%$ of the teenage participants believed that condoms increased promiscuity as an almost equal proportion of the 20-24 age group respondents indicated it was false.

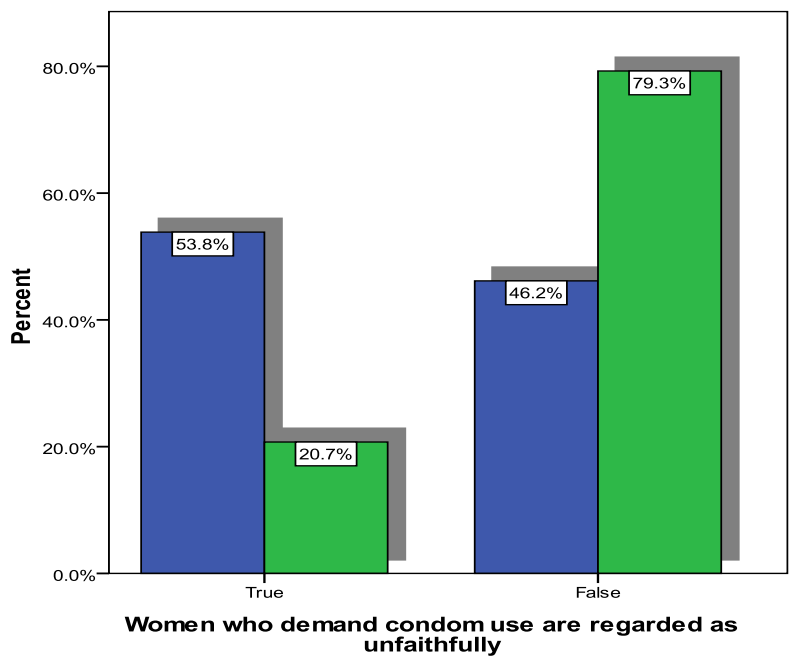

Age group

16-19 Years
$20-24$ Years

Figure 14: Women who Demand Condoms are Considered Unfaithful.

Over half of the teenage respondents (Figure 19 above) indicated that women who demanded condom use in a sexual relationship were considered unfaithful. Over $79 \%$ of the $20-24$ age group indicated that it was false. The fact that most teenagers consider women demanding condoms as unfaithful might be a major hindrance in negotiating condom use by this age group with their sexual partners, a factor that may increase their vulnerability and exposure to HIV infection. In addition, younger women are sought after by older men who consider them "safe" and are ultimately easy to lure into sexual activity especially through the use of money and other gifts.

Over $90 \%$ of all the respondents indicated that the use of condoms did not indicate a lack of love. Similarly, most respondents did not consider condoms as a source of frustration in sexual relationships.

\section{7. Reasons for not using the condom}

Individual participants held varied views on the use of condoms. In Namibia condoms are marketed and distributed both by government for free and the private sector at a nominal fee as a mode of HIV prevention especially against sexual transmission. As earlier indicated respondents had adequate knowledge on the prevention of HIV transmission and named the condom as a one of the measures. Respondents identified several factors that hindered condom use including a lack of adequate supplies, trust in their sexual partners and the desire to prove faithfulness as a means to secure financial security and avoid violent attacks from male sexual partners.

Further analysis however indicates that more respondents from towns over $88 \%$ reported trust in their sexual partners as a reason for not using condoms as those from villages reported trust at $61 \%$ as a hindrance to condom use (See figure 21 above). In this research it is generally debatable whether this trust is an honest achieved milestone in a relationship or a shortfall that female partners choose so as to attract and sustain relationships with their male partners who in turn are holders of their financial livelihood. Further since only female respondents were interviewed, it is difficult to ascertain whether the male counterparts are equally trusting. $40 \%$ of the respondents indicated that they agreed to sex without a condom for fear of violence from their male partners which could constitute a degree of coerced trust on the part of the female partners.

While the findings above are true, figure 22 above indicates that the majority of the respondents preferred sex without condoms. Over $66 \%$ of the respondents from towns indicated to prefer sex without condoms as $57 \%$ of the respondents from villages would opt for sex without condoms. It is generally believable therefore that the respondents could not have taken it upon themselves to negotiate condom use with their partners as a result of this reported personal preference. $40 \%$ of the respondents indicated not to acknowledge the benefits of condom use and that they did not know how to use condoms adequately.

Figure 23 above indicates that approximately $60 \%$ of the respondents are embarrassed to ask a partner to use condoms. This embar- 
rassment could be due to various factors such as gender, and other inter-linked causes described earlier including the perceived powerlessness about sex and sex matters by females and financial inequalities. What is definite is that with a $60 \%$ embarrassment level, condoms would largely be regarded a lesser prevention measure among female students.
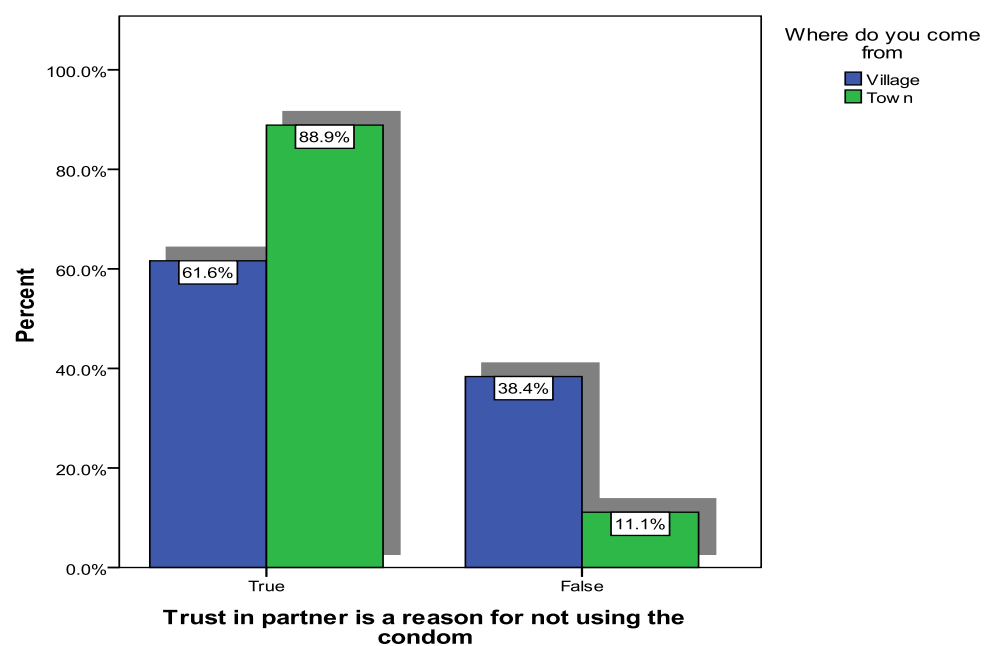

Fig. 15: Trust in Partner Hinders Condom Use.
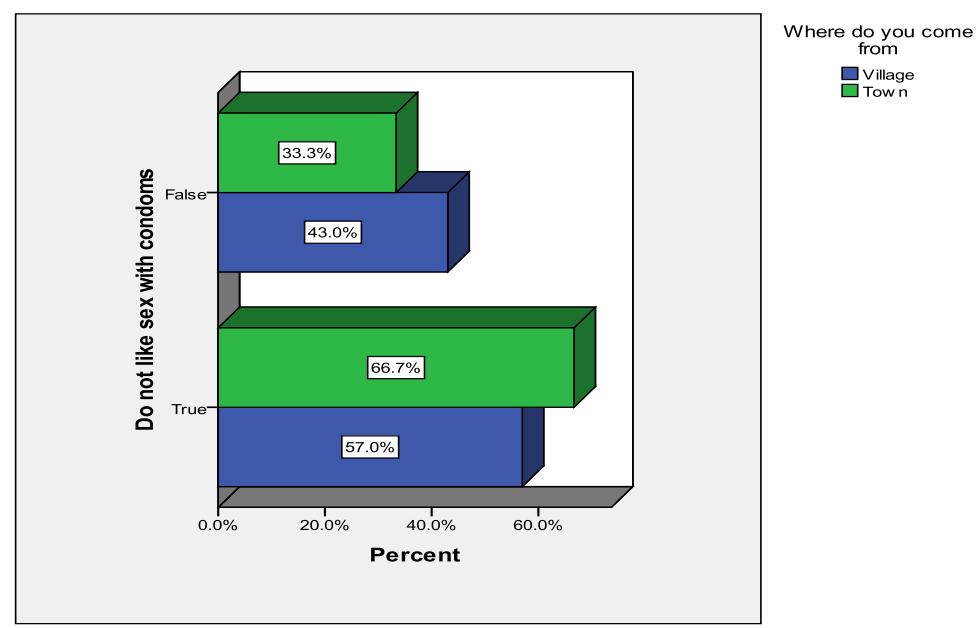

Fig. 16: Preference of Sex without Condoms

Embarrassed to ask partner to use condoms

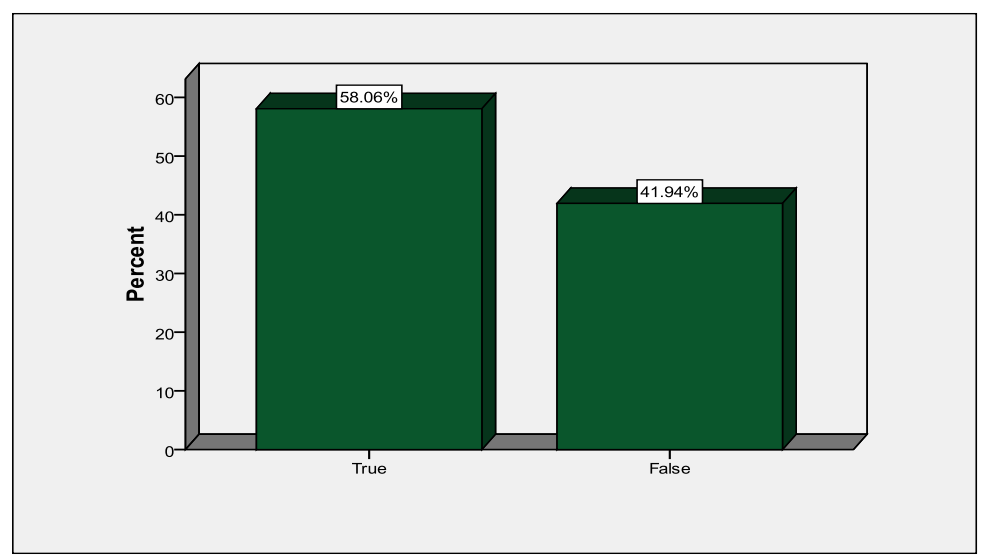

Fig. 16: Level of Embarrassment to Ask A Partner to Use A Condom.

\section{8. Perceived susceptibility to HIV and AIDS and STIs}

The majority of the respondents believed that HIV was a serious problem at UNAM Oshakati campus. Over $65 \%$ of the respondents believed they were at risk of HIV infection. Further, approximately $80 \%$ of the respondents indicated that having a long time relationship did not guarantee safety from HIV infection. Re- spondents contended at over $90 \%$ that exchanging sex to meet survival needs conferred a high risk to HIV infection for young female students. In addition, respondents adequately knew at over $96 \%$ that direct exposure to blood during sexual intercourse posed a great risk of infection and that the possibility of HIV transmission is greatest if a person has sexually transmitted infections and genital ulcers. 
On the contrary however, while the knowledge to susceptibility to HIV and AIDS can be asserted as adequate, respondent believed at $48 \%$ that it was impossible for someone to refrain from sexual activities once one becomes sexually active (See figure 24 below) This is indicative therefore that adequate knowledge of the facts did not necessarily result in commensurate behavior and attitude change aimed at HIV prevention.

\section{9. Assessment on youths' perception on HIV vulnera- bility associated with other socio-economic factors}

Respondents indicated that women and girls are more vulnerable to infection than young men of their age. This finding is in agreement with earlier results where respondents reported a low level of decision making powers over sexual matters, gender and financial inequalities. Overall, even younger men appear to be more influential over women in making decisions related to sexual matters.

Figure 27 below shows that nearly $100 \%$ of the respondents believed women seek multiple partners as a result of poverty to ensure economic stability. Limited income among women is indicated to force women into commercial sex work and prostitution.

Further, women may change their social environments regularly as they continue to search for survival. Change in social environ- ments, it was revealed, may result in a sense of anonymity which in effect may lead to reckless sexual decisions thereby increasing the risk of infection. Migration may offer sexual freedom which may facilitate the spread of HIV and AIDS.

Over $70 \%$ of the respondents (See figure 28 below) believed that cultural norms that make women subservient to men complicate prevention strategies among women. In addition, the disappearance of useful cultural values such as fidelity and abstinence results in increased vulnerability to HIV infection, respondents indicated.

Other than cultural norms that make women vulnerable, over $90 \%$ of the respondents indicated that there is a lack of access to health care services which left women susceptible to high levels of untreated sexually transmitted infections which in turn facilitate the spread of HIV and AIDS.

Excessive use of alcohol among men and women ultimately results in vulnerability for the women it was reported. Figure 29 below shows over $70 \%$ of the respondents indicating that alcohol impairs the ability to decide on sexual matters effectively.

Reduced ability to make decisions or control behavior results in increased risk taking thereby exacerbating the level of vulnerability to HIV infection.

Poverty makes females to opt for multiple partners to ensure economic stability

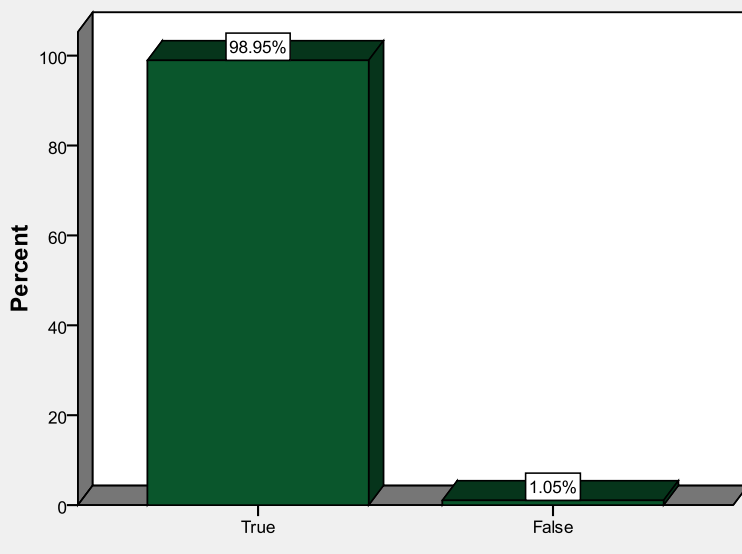

Fig. 17: Poverty Makes Women to Seek Multiple Partners for Economic Stability.

Cultural norms that makes women subservient to men complicates the prevention of HIV among women

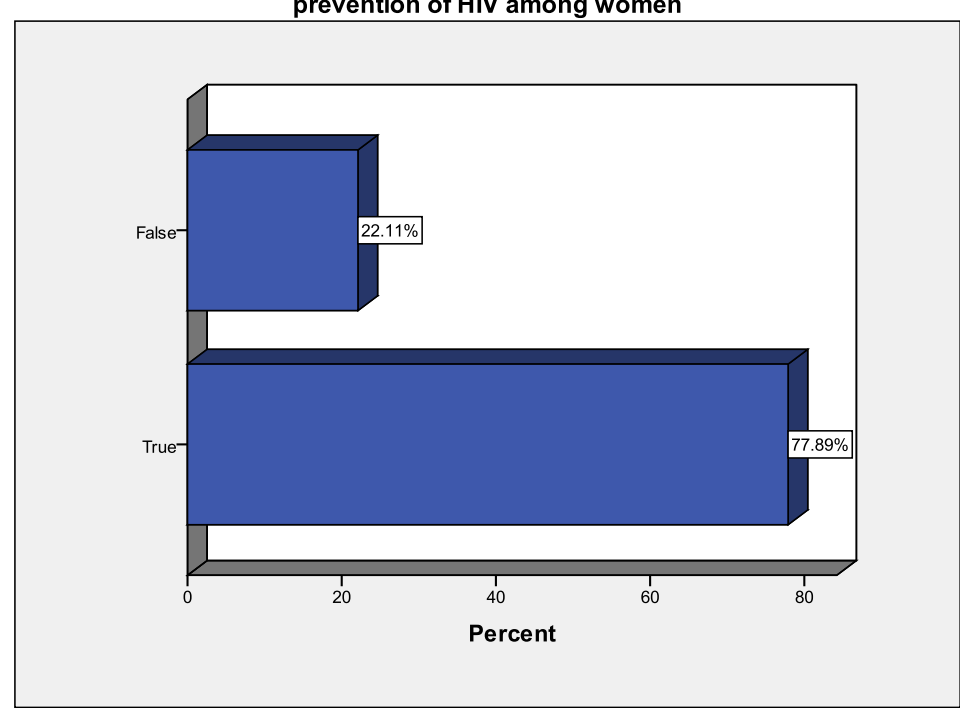

Fig. 18: Cultural Norms Complicate Prevention among Women. 


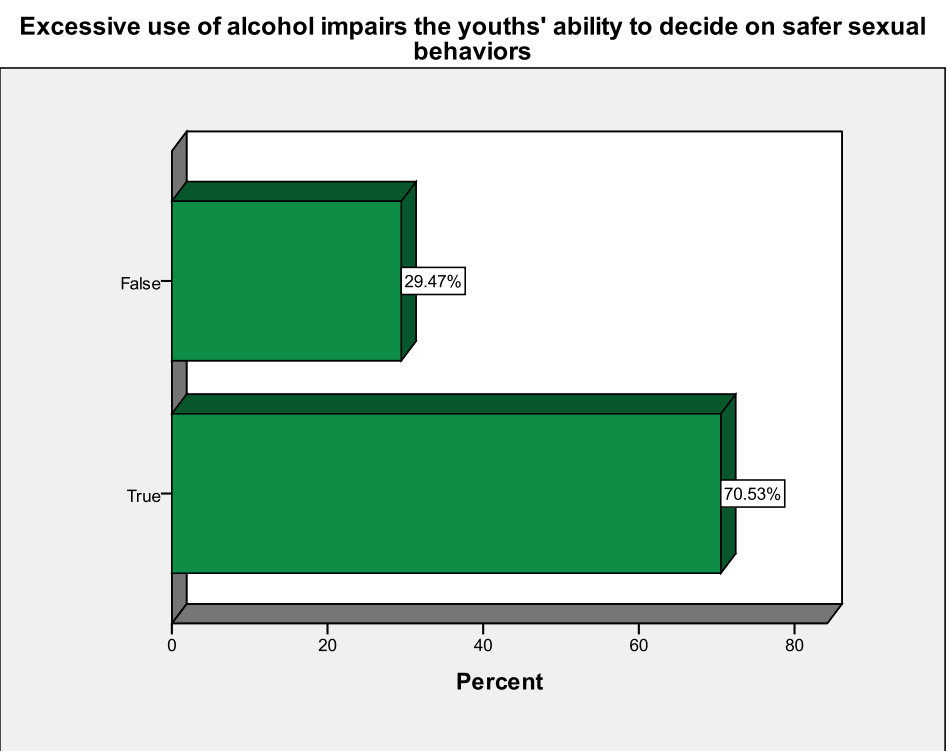

Fig. 19: Excessive Use of Alcohol Impairs the Ability to Decide on Safer Sexual Behaviors.

\section{10. Perception of vulnerability, structural and social factors}

In this section the researcher intended to find out respondent's perceptions on whether structural and social factors increased their vulnerability to HIV. A five level Likert scale system was used ranging from "strongly agree" to "strongly disagree". Factors assessed included poverty, age, education, life skills, and policy frameworks.

Figure 20: There are more females living in poverty than males Figure 34 above indicates that over 56\% of the respondents agreed that more females lived in poverty than males. It has been discussed in this study earlier that poverty increased women vulnerability to HIV and AIDS, forced women into commercial sex work and prostitution including attempts to have multiple sexual partners for economic survival.

Age and a perpetual lack of collateral guarantees often limit young women's ability to access financial credit which could have been used to advance into usable businesses that contribute to economic emancipation. Further, more women than men as a result remain at the lower end of the socio-economic spectrum. The disadvantage of lack of access to financial credit, limited opportunity and ability to pay for education among women results in large numbers of women without sufficient life skills which aggravates the risk to HIV.

Generally, there is a lack of policies that are tailored to address problems affecting young women which undermine the effectiveness of prevention strategies among this group.

\section{11. Perception of vulnerability: behavioral factors}

Using a five level Likert scaling system, respondents were assessed on some behavioral factors that could increase their vulnerability to HIV and AIDS. These factors included peer pressure, cross-generational relationships and multiple partners.

Respondents pointed out that peer pressure increased the risk of HIV infection among young female student nurses. Figure 35 below shows that over $86 \%$ (a combination of agree and strongly agree) of the respondents believed that peer pressure greatly increased their vulnerability and risk of exposure to infection.

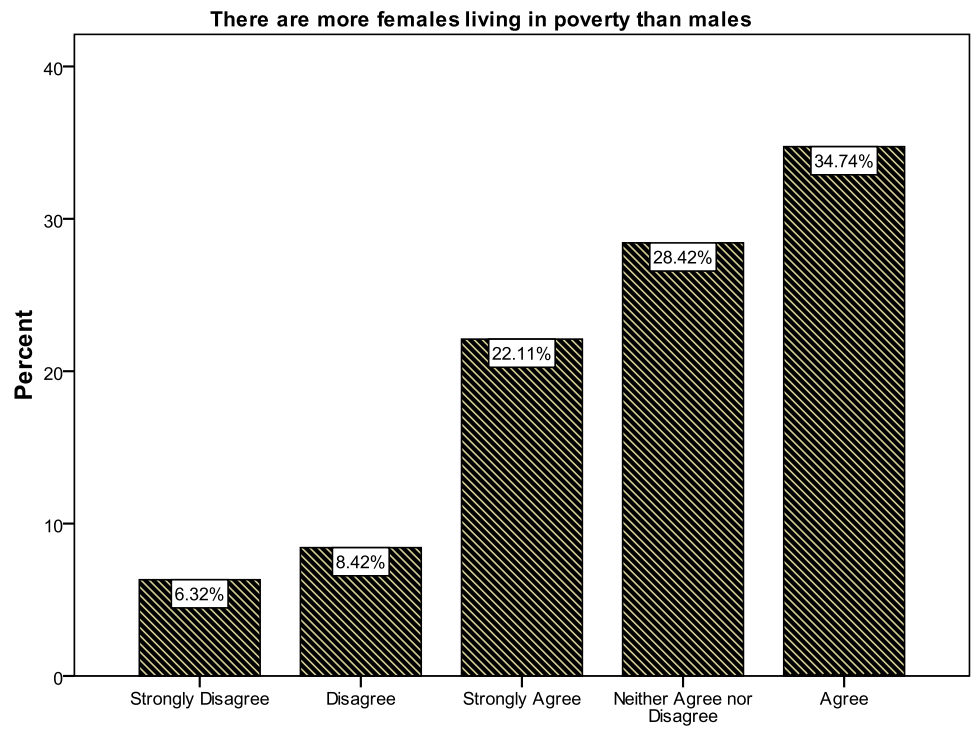




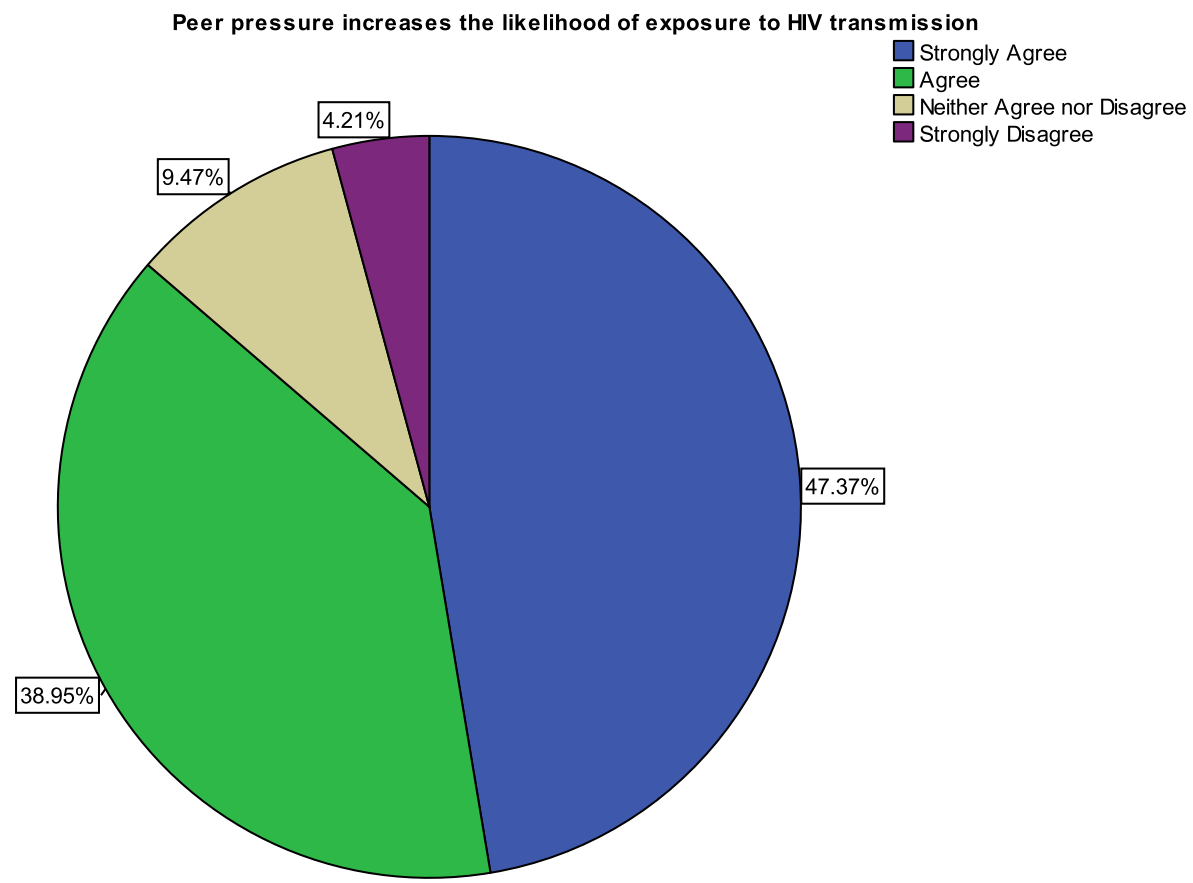

Fig. 21: Peer Pressure Increases the Likelihood of Exposure to HIV.

In addition respondents generally indicated that a lack of information regarding HIV from the media results in an elevated influence among young women to engage in risky sexual practices. The media was seen as a safer and freer source of information since many young women are constrained by several cultural provisions that hinder open discussions with parents and other elders on matters concerning sex.

Respondents revealed that men believed that young women are most likely not infected and as a result looked at them as a class of "safe prey" who were severally targeted for sexual exploitation. For this reason, cross-generational sexual relationships were a common phenomenon which is reportedly sustained by the belief that young women can be financially secure if in a relationship with older men. Figure 36 below indicates that respondents are aware that young women involved in cross-generational relationships are vulnerable to HIV infection.
Over 59\% agreed that cross-generational sex posed a risk of exposure to HIV infection among young women involved in such relationships. In this kind of relationships, respondents revealed that it was inevitable to have unplanned pregnancies. Further, relationships entered into for reasons of financial security can easily become a form of transactional relationship and invites added risks and increased levels of vulnerability. It has been earlier revealed by this study that income inequalities lead to heightened levels of exposure to HIV and vulnerability of especially young women. In addition, protection is a challenge to achieve in relationships bent on securing financial stability as one partner with the "right gender", resources and age easily manipulates the affairs of the relationship.

On the other hand, figure 37 below reveals that respondents acknowledge that exposure to HIV increases with the number of partners.

\section{Young women involved in cross generational sex are vulnerable to HIV} infection
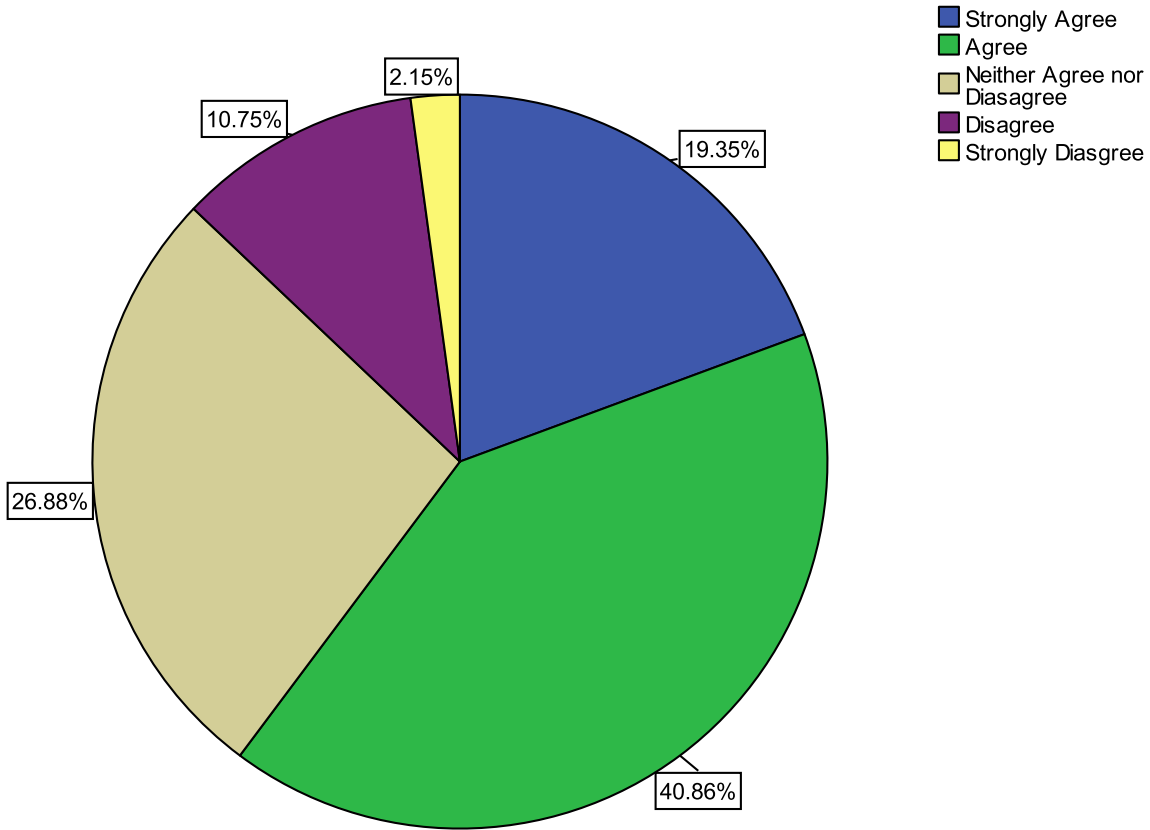

Fig. 22: Young Women Involved in Cross Generational Sex are Vulnerable to HIV Infection. 


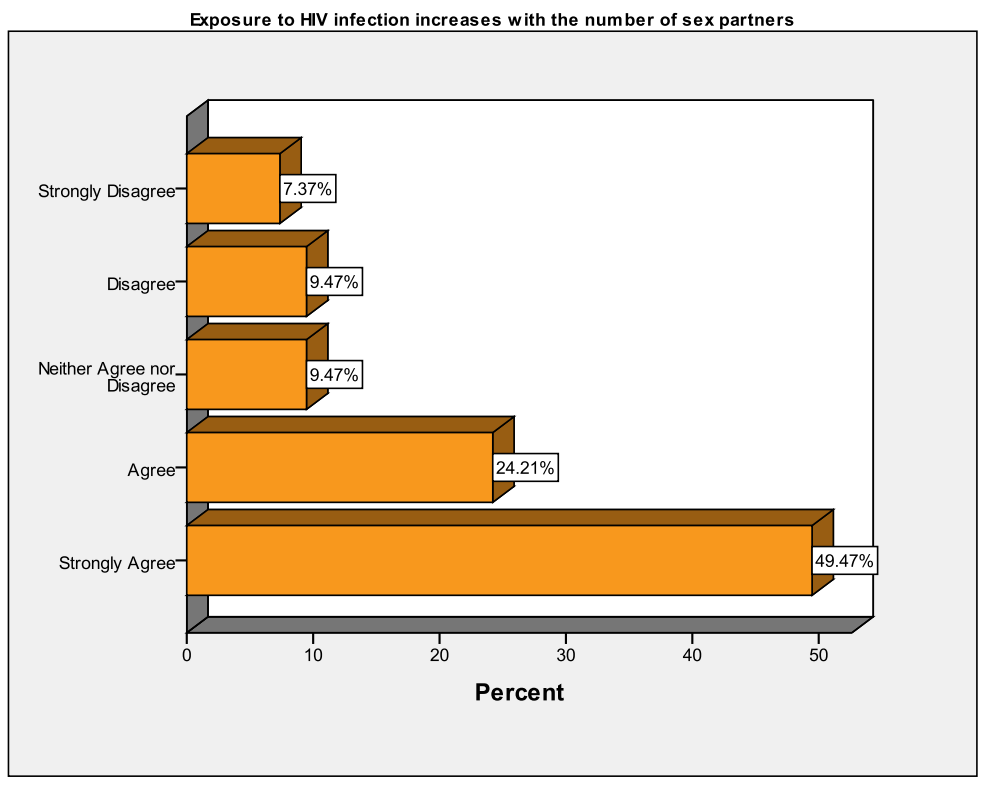

Fig. 23: Exposure to HIV Infection Increases with Number of Partners.

Approximately $74 \%$ indicated that increase in the number of partners increased the risk of getting infected. Generally therefore, respondents appreciate the risk and risk levels involved in having more than one sexual partner.

\section{Discussions}

The study findings emerged from the survey and focus group discussion was combined in this discussion. The factors that were identified making student nurses vulnerable were categorized in six major categories: knowledge about HIV and AIDS, risky behaviors, barriers to access of health care, gender inequality and violence, attitude towards condom use and HIV vulnerability associated with other socio-economic and cultural factors. The existence of these factors creates imbalance and unequal exposure to HIV infection among various age groups and regions. The study findings were supported by many authors as it appearing from the subsequent paragraphs. HIV is a very serious threat to young people in Namibia (UNAIDS/WHO 2007, UNICEF 2008).

Overall, Participants identified sexual intercourse as a major mode of HIV transmission (Anderson \& Beutel, 2007).In both groups, respondents were open about the fact that they were sexually active and had sexual partners such as boyfriend (James at el. 2004), s. However, it was revealed that sexual intercourse may not be "protected" referring to the use of condoms and in cases where condoms are used; correct application of the prevention method was doubted by most respondents ( Salazar et al. 2005). The median age at first intercourse for women is 19 years, but one third of women reported to have had sexual intercourse by the age of 18 (MoHSS Namibia Demographic and Health Survey 2003). National health statistics reported that $60 \%$ of the age group 16-19 are sexually active and $6 \%$ of girls reported to have had sex before age 15. It is noted that teenage pregnancy is very high in Namibia with girls at $39 \%$ either pregnant or have a child by the time they are 19 (MoHSS \& UNICEF 2004). Knowledge alone is not enough to assure 'safe' sexual behavior (Visser 2005). A significant number of young people have superficial knowledge about prevention for sexually transmitted diseases and infections including HIV (Mba 2003).

Besides unprotected sexual intercourse there are also other modes facilitating HIV transmission. Respondents revealed that HIV can be transmitted from an HIV positive mother to her unborn child. HIV and AIDS is far more than a medical and biological problem around the world (Hasnain 2005)

Blood transfusion was reported as another mode of HIV transmission. However this was challenged by one of the respondents say- ing that the Namibia government through the blood transfusion service has a meticulous screening system for donated blood which has resulted in safe blood at all blood banks and hospitals in the country. The respondent believed that blood transfusion no longer posed a risk of HIV infection and was no longer a mode of transmission in Namibia.

A respondent submitted that the only $100 \%$ method of HIV prevention was abstinence from sex. Generally, most members of the group supported this as a means of prevention especially because they viewed sexual intercourse as posing the greatest risk of them all to HIV infection for the young female student nurses. Participants also revealed that the consistent and correct use of condoms is another effective method of HIV prevention. This was qualified further by participants charging that femidoms (female condoms) were stronger and more effective and should be made available. Most respondents expressed concern that only male condoms were widely available placing their male counterparts at a greater advantage in discussing and practicing safer sex, the use of condoms. From the professional point of view, respondents submitted that avoiding the re-use and or sharing of needles and other sharp instruments can help prevent HIV transmission. Student nurses encouraged each other to always work with and close to dispose containers where used needles and other sharp instruments can immediately be disposed.

To prevent infection through direct contact with infected blood, the respondents expressed that dressing in protective clothing in laboratories, the labor ward and theatre could avert the risk of infection. Furthermore, accidental contact with blood such as through needle pricking or accidental occupational cuts should be immediately reported to so as to receive immediate care especially the administration of the Post Exposure Prophylaxis (PEP) and counseling which is available at the hospital.

Overall, respondents indicated a high degree of awareness of risky behavior ranging from accepting gifts in exchange for sex to multiple sexual partners. Findings reveal that over 96 . \% perceived that multiple sexual partners constituted risky behavior (Oguntibeju et al. 2003).This finding is in agreement with the general view that increase in sexual partners is associated with HIV infection (Visser 2005; Chwee et al. 2007; Sabone et al. 2007).

Over $94 \%$ of the respondents perceived sex in exchange for gifts as risky. Generally young girls in Namibia accept various favors including gifts from men usually older than them and accept to have sex with them as a means to appreciate the gifts they receive (Simbayi et al. 2004). Findings from the study reveal that young women up to $91.6 \%$ exchange sex for economic stability Female students revealed that economic needs which included housing, transport, tuition fees and food exposed many young students to 
the risk of exposure to HIV as they sought able men who meet the costs of these needs and reward them with sex Women have limited access to resources they need to earn income and ensure their own and families wellbeing (Otaala, 2003).

Further over $86 \%$ of the respondents agreed that transactional sex constituted risky behavior (USAID \& FHI 2006). As opposed to sex in exchange for gifts, transactional sex involves a deliberate choice to offer sexual pleasures in exchange for money or monetary equivalents.

$70.5 \%$ of the respondents asserted that bad attitudes of health care workers are a major barrier to the access of HIV and AIDS health care service (Andrewin \& Chien 2008). This finding is of particular significance since the respondents are themselves nurses in the making and yet reveal strongly that bad attitudes of care providers prevent them from using available health care services It is vital to integrate peer education with reproductive health and HIV services to improve on the distribution of opportunities to access health services among young women (USAID \& FHI 2006), Stigma hinders using of services such as voluntary counseling and testing (Holzemer et al. 2007. In addition, 68\% of the respondents indicated that women are shy in seeking health care services and that is a major barrier (Mba 2003). This finding is again of greater significance considering that the respondents are women and particularly university students who constitute the elite of the communities they live in.

Over $90 \%$ of the respondents indicated that young women lacked the power to decide on the timing of sex (MacLean 2006). This finding is in agreement with the previous revelation as young women continue to believe that their vulnerability is circumstantial and controlled by other factors, in this case, the men who are perceived to have control over the timing of sex. Further, approximately $70 \%$ of the respondents believed that young women have no ability to make correct decisions on the conditions under which sex should occur. Again, a perception that someone else particularly connoting the man controls even the conditions under which sex occurs and that the female counterpart is on the receiving end which compromises the safety of young women in the face of HIV and AIDS The most common relationship where women exchange sex for economic stability involves usually older men who could be married with families (Pettifor et al. 2005). 83\% of the participants indicated that women involved in cross-generational sexual relationships have little to no bargaining power over the functioning, safety and negotiation of sexual matters as the men are not only older but hold the economic lifeline of the young women (Weissman et al. 2006). The above often results in increased vulnerability to sexual abuse and harassment for many young women (Msiska 2003). Results from this study reveal that $100 \%$ almost all respondents are aware that sexual harassment increases their risk to HIV infection. The fear of and exposure to harassment is exacerbated by identified powerlessness in decision making by young women over sexual matters (Weissman et al. 2006), income inequalities that result in women using sex as a tool to please men and sustain relationships even if they are risky for the purpose of accessing and meeting their basic needs. Lack of economic empowerment increases youths' vulnerability to HIV infection (Iipinge et al. 2004; MacLean 2006; Weissman et al. 2006). HIV prevention will not be a reality if we fail to address the reality of the daily lives of young women (Ackermann \& de Klerk 2002).

On the contrary however, findings of the study reveals that over $76 \%$ of the teenage respondents believed that condoms increased promiscuity as an almost equal proportion of the 20-24 age group respondents indicated it was false. Over half of the teenage respondents indicated that women who demanded condom use in a sexual relationship were considered unfaithful (MOHSS Report of the 2006 National HIV Sentinel Survey; MoHSS Report of the 2008 National HIV sentinel survey). Over $79 \%$ of the $20-24$ age group indicated that it was false. The fact that most teenagers consider women demanding condoms as unfaithful might be a major hindrance in negotiating condom use by this age group with their sexual partners, a factor that may increase their vulnerability and exposure to HIV infection. In addition, younger women are sought after by older men who consider them "safe" and are ultimately easy to lure into sexual activity especially through the use of money and other gifts. Some studies found that some young women are not in position to insist on condom use as they stand a chance to lose economic benefits (James et al. 2006).

HIV infection affects primarily the productive age range in the population with $55 \%$ of the new infections being among women (Oguntibeju et al. 2003; Shapumba et al. 2004). Young people are, to a differing degree, governed by external structures that determine the choices they have available to them and influence their preferred outcomes (Gregson et al. 2005). Age often limits the youths' ability to seek formal employment, to own land, to receive financial credit and access other livelihood assets, yet expectation and the need for the youth to contribute to family livelihood make them more vulnerable to poverty and exploitation (Mba 2003).

A participant who was variously supported indicated that enrolling at the university initiates a student to a whole new cosmopolitan place that brings together individuals and groups of people from different backgrounds, culture, and behavior and belief systems. The first step for every student is to devise means to belong, adapt and change. This process of integration comes with the creation of new friendships which may also be sexual relationships. These relationships without known history and background pose a potential risk factor to HIV infection for university students.

The University does not have an on campus hostel. This compromises the security of students who have to travel to the university in the early morning and late evening hours to and from campus. Female students may become easy targets at such hours for perpetrators of rape and therefore the risk of HIV infection.

A further risk factor was identified as the fact that the available hostel does not have the capacity to accommodate all students. For students who do not have accommodation provided at the hostel, they have to find private accommodation. Usually, private accommodation is expensive and parents cannot readily afford its cost. Female students therefore resort to finding especially male partnerships and friendships geared towards relieving this cost. These partnerships and relationships eventually result in girls offering sexual pleasure in exchange for meeting accommodation costs. In addition, most families do not afford luxuries for their children such as jewelry, transport, cell-phones, laptop computers etc. Female students therefore seek out male partners who can afford these luxuries for them. Equally, sex is offered as a befitting reward for the men. Therefore, the young women are forced to use various economic coping mechanisms which most of the time involve the option for economic dependency on older men to support them (Pettifor et al. 2005; Campbell et al. 2005). Females opt for multiple partners to ensure economic stability. This was believed during the focus group discussion as a common practice and that it posed a huge risk to HIV infection as it reduces negotiation powers for safe sexual practices on the side of the female students.

Respondents revealed that the location of the campus itself is a risk factor. The northern campus is surrounded by shebeens, (local liquor outlets) bars and mainly other alcohol outlets "a potentially dangerous neighborhood". Students are regular revelers at these places. Students are involved is excessive alcohol use, smoking and probably the use of drugs. Substance abuse especially the abuse of alcohol is a major risk factor in HIV transmission and consequently, students may be infected as a result of this (Shapumba et al. 2004); Sabone et al. 2007).

The university like any other training institution, it was revealed has great potential for peer pressure and its bad effects. Most students become victims of decisions and actions that are a result of group influence. This risk is enhanced by the desire to belong and be an accepted part of the conventional norms of a particular group of students. Included in the risky decisions and practices students may engage in include alcohol abuse, multiple sexual partners, smoking and general irresponsible behavior.

Participants were asked to identify cultural practices that posed a risk to female student nurses in terms of HIV infection. The different cultural practices were discussed and it was revealed that in 
the "Oshiwambo" culture, sick people are still taken to traditional healers ("Oonganga") for treatment. Generally, some traditional healers demand that they have sexual intercourse with their female clients in the process of prescribing and administering treatment Such sexual intercourse is variously risky as no protection is used and the fact that such healers have sexual intercourse with several people is of great risk (Shapumba et al. 2004).

Most traditions of the participants of the focus group discussions do not accept the use of condoms in marriages. Participants identified men as having various extra marital relationships and that this posed a risk of infection to most married women. In Namibia growing numbers of new infections are occurring in marriages it was revealed.

Knowledge deficit is aggravated by wrong beliefs among men who believe that HIV can be cured by having sexual intercourse with a virgin (Simbayi et al. 2005). Many young women experienced forced sex (Salazar 2005) which is unsafe and causes injuries inside the vagina. Any small injury provides an open door to the virus (MoHSS \& UNICEF 2004).

In the Otjiherero tradition, it is believed and practiced that the uncle of the bride engages in sexual intercourse with her first before marriage as a means to confirm that the girl was actually a virgin before marriage. Since the uncle is usually an older person it is possible that he could be infected with HIV and therefore passes the virus on to the young bride (Simbayi et al. 2005).

It was revealed also that most cultures in Namibia still practice wife inheritance. Should a husband die, one of the deceased's brothers is selected as the husband of the widow. This does not only pose a risk to woman should the man be infected but to the man should the widow be infected with HIV (Mufune 2003).

Generally, young female student nurses believed that relationships were for sex. Participants argued that on face value, a relationship without sex did not befit the "current" definition. As such every relationship that was initiated between a boy and girl was predetermined to eventually end up in sexual intercourse it was revealed. Therefore each relationship poses a risk to HIV infection for everyone involved. The cultural norms that define men as superior to women make it difficult for women to protect themselves from HIV infection (Jackson 2002). The disappearance of traditional values such as fidelity and abstinence are also contributing to the spread of HIV epidemic (Oguntibeju et al. 2003). There is also some notable cultural continuity. For instance, it remains a taboo to discuss sex in public, especially for people of different ages. This also applies to people of the opposite sex also may not discuss sexual issues even in marriage and cohabiting relationships (Mufune 2003). This makes it difficult for parents to teach their children about HIV. Where culture expects women to be passive and subservient to men, young women have little or no control over decision-making relating to sexuality, nor the sexual behavior of their male partners or the use of condoms for prevention of sexually transmitted diseases, HIV and pregnancy (Pettifor et al. 2005).

Individual responses were assessed against consensus within the general group and those that gained general agreement are recorded. A respondent expressed that most female students had low self-esteem which inhibits them from making responsible informed decisions including negotiation for safer sexual practices. The participants generally agreed that low self-esteem was further exacerbated by the inability to afford basic needs which in turn increased risk levels to vulnerability as men very easily take advantage of women in such circumstances (WAD, UNAM, \& NPS 2006).

Participants revealed that many students had developed resistance to change and ignored HIV messages. It was revealed that students understood HIV infection to be like any other disease and that they didn't need to take any precautions for its prevention (Van Niekerk \& Kopelman 2006). Female students for example preferred to attend family planning clinics and prevent themselves from getting pregnant as opposed to HIV. They would reach out for anti-pregnancy pills a lot easily than to condoms. This increased every student's vulnerability to HIV infection.
Respondents generally believed that women were easily manipulated by their male counterparts for various reasons. Such reasons range from gender inequalities, to the construction of culture and cultural norms, economic disparities and societal pressures. For these reasons, women find themselves at the receiving end in terms of HIV infection. A greater number of participants felt that they were vulnerable due to excessive peer pressure at the University. Furthermore, a respondent argued that by nature, a female membrane (referring to the lining of the female sexual organ) is easily bruised and therefore women can get HIV more easily that way than men (Barnett and Whiteside 2002).

The researcher inquired of how the respondents perceived risk to HIV as individuals. Obviously, every participant perceived the nursing job as the primary risk factor to each one of them. Every student nurse perceives their job as risky and that they needed to exercise extra care in their interaction with patients to minimize accident needle pricks, and direct contact with blood. The average risk of HIV infection after a single percutaneous exposure is $0.3 \%$ among the health workers (Mantillas 2008; McDonald \& Ruiters 2005). Health workers have low but measurable risk of HIV infection after a single percutaneous exposure to infected blood or body fluids (MoHSS National guidelines for antiretroviral therapy 2007b). The gap in HIV prevention remains a challenge (Anderson \& Beutel 2007).

As female student nurses, the respondents expressed fear over the safety of their relationships since they reported to have boyfriends. Every respondent agreed that multiple sexual partners increased the risk to HIV infection and this could be a factor of fear that their boyfriends (or sexual partners) were not necessarily faithful (Campbell et al. 2005)

It was repeated in this question that the location of the campus increases individual student's vulnerability because it is in one surrounded by a risky neighborhood and that hostels off campus compromised girl's safety and could easily expose them to HIV infection.

\section{Limitations}

Due lack of resources, time and financial constraints the researcher found it difficult to conduct the study at all four University of Namibia campuses in Northern Namibia. As a result generalization of the research findings to the three Northern Campuses, student nurses who registered with the centre for external studies and foundation program students is not possible.

\section{Conclusions and recommendations}

\subsection{Conclusions}

The findings indicated clearly that young female student nurses have adequate level of knowledge about HIV and AIDS. They articulated the various risk factors, modes of transmission, prevention and care including knowledge about support systems available. The results further indicate that the available knowledge and positive attitudes among the respondents did not result in positive lifestyles and responsible behavior that could have helped prevent further spread of the virus.

Young female student nurses continue to be largely at risk of HIV infection due to gender inequalities, income inequalities and generally poverty, environmental circumstances, reduced risk perception, poor attitudes towards condom use, culture and a general dominance of men over women.

It is further concluded that the major barriers to access services is limited by bad attitudes of health service providers, women shyness in seeking health care services and stigma still attached to HIV and AIDS

The findings further indicate a significant level of life skills including negotiation skills available among respondents. However, there was no indication of an effective application of such skills in 
influencing the sexual behavior and attitudes of respondents against HIV and AIDS

Effectively addressing HIV and AIDS requires multiple approaches that combine social, economic and political factors. Issues such as poverty, migration patterns, alcohol consumption, compromised assertiveness, transactional relationships, cross generational relationships, gender-based violence, are some of the most critical issues revealed as requiring concerted attention from this study.

\subsection{Recommendations}

Here are the recommendations the study has generated to prevent the spread of HIV among young student nurses at the University of Namibia:

- The lecturer who teaches the module on HIV and AIDS should encourage the students to internalize the preventive part of the module so that the students are able to see themselves as "at risk individuals" when not practicing what they preach.

- Encourage young women who are not yet sexually active to delay sex until they are in the right sexual relationships.

- Educate youths on safer sex practices to improve their biological resistance to HIV infection.

- Develop appropriate programs to support young women with various skills training in assertiveness, negotiation, decision making, interpersonal and personal control to help young women reduce risk to HIV infection.

- Train and create awareness on correct and consistent use of condoms among youths. It is beneficial to train young men to respect and accept 'no' to sex from their female counterparts.

- Promote gender equality in education, employment and in relationships. Encourage peer support to reduce stigma against youth infected with HIV.

- Develop active approaches among youths to address stigma and discrimination.

- There is need to strength a wellness centre at the University to improve and intensify the services for psychosocial support and access to youth-friendly services and reproductive health.

- Motivate women to seek early treatment for sexually transmitted infection including HIV to reduce HIV new infection.

- Create strategies that promote good practices on incomegenerating activities tailored to meet economic needs of young women including short courses on alternative income generating skills to empower young women who use their bodies as capital (source of income).

- Use back up strategies by encouraging spiritual stability of the youths in the community.

- Church leaders should endorse condom use when abstinence fails.

- Encourage youths to avoid risky settings where alcohol and substance is abused.

- Promote young women access to high education and training to improve their knowledge on HIV, risk reduction, and improved access to employment opportunities.

- Teach youths the basics of practicing non-penetrating sex.

- Educate youths about risks involved in cultural practices and avoid dry and forced sex which increases the likelihood of severe genital rubbing.

\section{Acknowledgement}

The authors would like to thank the participants in this research for sharing their lived experiences and value the contribution made by everybody for the completion of the research.

\section{References}

[1] Ackermann, L \& de Klerk, G. W. (2002). "Social factors that make South African women vulnerable to HIV infection". Department of Sociology, University of Free State, Bloemfontein: South Africa.

[2] Anderson, K. G. \& Beutel A. M (2007) HIV/AIDS prevention knowledge among youth in Cape Town, South Africa. Journal of Social Science 3(3), 143 - 151, 2007 ISSN1549-3652. Science Publications

[3] Andrewin, A. \& Chien (2008) "Stigmatization of Patients with HIV/ADS among doctors and nurses in Belize". AIDS patient care and STDs, Volume 22 (11), 897-906. http://dx.doi.org/10.1089/apc.2007.0219.

[4] Barnett, T. \& Whiteside, A (2002) AIDS in the Twenty-first Century, Disease and Globalization, Palgrave Macmillan: New York. http://dx.doi.org/10.1057/9780230599208.

[5] Brink, H. I. (2006). Fundamental of Research Methodology for Health Care Professionals. JUTA \& COMPANY LTD, Cape Town.

[6] Burns, N. \& Grove, S.K. (2005). The Study guide for practice of nursing research, Conduct, Critique and utilization. $5^{\text {th }}$ ed. Arlington: Texas.

[7] Campbell, C., Foulis, C. A. Maimane, S. \& Sibiya, Z (2005). The impact of social environments on the effectiveness of youth HIV prevention. A South African case study, AIDS care, 17(4), 471-478. Routledge Taylor \& Francis Group. http://dx.doi.org/10.1080/09540120412331319705.

[8] Chwee, L. C., Eke-Huber, E., Eaddy, S., \& Collins, J. K (2005) Nigerian College students. HIV knowledge, perceived susceptibility for HIV and sexual behaviors. College Student Journal, Vol. 39 Issue 1, 60-17. Pretoria, South Africa.

[9] De Vos, A. S., Strydom, H. Fouche, C. B.\& Delport, C. S. L. (2005). Research at grassroots for the social science and Human service professions. $3^{\text {rd }}$. ed. Van schaik publishers: Pretoria, South Africa.

[10] Fink, A. (2003). How to ask survey questions: The survey kit. $2^{\text {nd }}$. Ed. SAGE Publications; London. http://dx.doi.org/10.4135/9781412984393.

[11] Government of the Republic of Namibia \& United Nations Children Emergency Fund (2004) My Future Is My Choice. Life Skills Programme. Windhoek, Namibia.

[12] Gregson, S. Nyamukapa, C. A. Garnett, G. P. Wambe, M. Lewis, J. J. C. Mason, P. R. Chandiwawana S. K. \& Anderson, R. M (2005) $H I V$ infection and reproductive health in teenage women orphaned and vulnerable by AIDS in Zimbabwe. AIDS care, Routledge, Tailor \& Francis Group. 17(7), 785-794. http://dx.doi.org/10.1080/09540120500258029.

[13] Hasnain, M (2005) Cultural approach to HIV/AIDS harm reduction in Muslim Countries. Harm reduction journal, 2 (23).

[14] Holzemer, W. L., Uys, L. R., Chirwa, M. L., Greeff, M., Makoae, L. N., Kohi, T. W., Dlamini, P., Stewart, A. L., Mullan, J., Phetlhu, R. D., Wantland, D. \& Durrheim, K. (2007) Validation of the HIV/AIDS stigma instrument -PLWA (HASI-P), AIDS care. Routledge, Tailor \& Francis Group. 19(8), 1002-1012.

[15] lipinge, S. Hone, K. \& Friedman, S (2004) the relationship between gender roles and HIV infection in Namibia. University of Namibia: Windhoek. International Council of Nurses \& CANAC (2006) Nurses at the forefront of HIV/AIDS. Report on International Nurses' forum. Toronto, Canada.

[16] Jackson, H. (2002). AIDS AFRICA: Continent in crisis. SAfAIDS, Harare.

[17] James, S. Reddy, S. P. Taylor, M. \& Jinabhai, C. C (2004) Young people, HIV/AIDS / STIs and sexuality in South Africa. The gap between awareness and behaviors. National Health Promotion Research and Development Group, Medical Research Council, Cape Town, South Africa, Department of Community Health. Nelson R. Mandela Medical School. University of Natal. Durban, South Africa. Taylor \& Francis. Act Pediatric, 93, 264-269. http://dx.doi.org/10.1111/j.1651-2227.2004.tb00718.x.

[18] MacLean, A (2006) Community involvement in youth reproductive health and HIV prevention. A Review and analysis of the literature, Family Health International/Youth net. Arlington, Virginia 22201.

[19] Mantillas, J. R (2008) Protecting health workers from occupational exposure to HIV through global campaigns. Public Services International, International AIDS conference.

[20] Mba, C. J (2003) Sexual behavior and the risk of HIV/AIDS and other STDs among young people in Sub-Saharan Africa. A review.

[21] McDonald, D. A. \& Ruiters, G. (Eds.) (2005) who cares for health care workers? The state of occupational health and safety in $\mathrm{Mu}$ - 
nicipal health clinic in South-Africa, Municipal Services Project, Occasional Papers Series no8.

[22] Ministry of Health and Social Services (2003) Namibia demographic and health survey. Namibia: Windhoek.

[23] Ministry of Health and Social Services (2006) Report on the 2006 National HIV Sentinel Survey. HIV prevalence rate in pregnant women, biannual survey 1992-2006. Windhoek, Namibia.

[24] Ministry of Health and social Services (2007) A guide to HIV and AIDS workplace programmes. Windhoek, Namibia.

[25] Ministry of Health and Social services (2008) Report on the 2008 National HIV Sentinel Survey. HIV prevalence rate in pregnant woman. Biannual survey 1992-2008. Namibia, Windhoek.

[26] Msiska, R. M (2003) Mainstreaming HIV and AIDS into poverty reduction strategies. University of South Africa, Pretoria.

[27] Mufune, P (2003) Changing patterns of sexuality in Northern Namibia. Implication for the transmission of HIV/AIDS. Culture, Health \& Sexuality. Taylor \& Francis Ltd. Vol. 5, (5), 425-438. http://dx.doi.org/10.1080/136910501165631.

[28] Oguntibeju, O. O. Van Chalky, F. E. \& Van Den Heaver, W. M. J (2003) the epidemic. Factors responsible for the epidemic and the impact of HIV/AIDS. School of health technology Faculty of Health \& Environmental Science. Bloemfontein, South Africa.

[29] Otaala, B (2003) Human Immuno Virus/Acquired Immune Deficiency Syndrome. Government leaders in Namibia responding to the HIV/AIDS Epidemic issue number 6. University of Namibia. Windhoek, Namibia.

[30] Pettifor, A. E., Rees, H. V., Kleinschmidt, I ., Steffenson, A. E. MacPhail, C., Hlongwa-Madikizela, L., Vermaak, K. \& Padian, N. S (2005) Young people's sexual health in South Africa. HIV prevalence and sexual behaviors from a nationally representative household survey. AIDS 2005. Lippincott Williams \&Wilkins. 19(14), 1525-1534.

[31] Sabone, M., Ntsayagae, Brown, M. S., Seboni, N. M., Mogobe, K. D. \& Sebego, M (2007) Perceptions of undergraduate students not participating in HIV/AIDS prevention in Botswana. International Nursing Review, 54, 332-338. http://dx.doi.org/10.1111/j.14667657.2007.00544.x.

[32] Salazar, X., Caceres, C., Rosasco, A., Kegeles, S., Maiorana, A., Garate, M., Coates, T (2005) The NIMH collaborative Human Immuno Virus/Sexual Transmitted Infections prevention trial group. Vulnerability and sexual risks. Vagos and vaguitas in a low income town in Peru. Culture, Health \& Sexuality. Routledge, Taylor \& Francis Group Ltd. 7(4), 375-387.

[33] Shapumba, T. Apollus, F. Wilkinson, W. \& Shifiona, N (2004) Socio-cultural and operational research approach to adolescent and youth sexual and reproductive health. Oshana Region. University of Namibia, Windhoek.

[34] Simbayi, L. C. Kalichman, S. C., Jooste, S. Cherry, C. Mfecane, S. \& Cain, D (2004) Risk factors for Human Immuno Virus/Acquired Immuno Deficiency Syndrome among youth in Cape Town. South Africa. Acquired Immuno Deficiency Syndrome and behavior, Volume 9 , No.1.

[35] Talavera, P. (2002). Challenging the Namibian perception of sexuality. A case study of the Ovahimba and Ovaherero culture-sexual models in Kunene North in an HIV /AIDS context. Windhoek, Grasberg Macmillan Publishers.

[36] UNAID/ World Health Organisation (2007) Acquired Immune Deficiency Syndrome epidemic update.

[37] US AID \& FHI (2006) Youth Peer education. Washington DC, USA.

[38] Van Niekerk, A. A. \& Kopelman, L. M (2005) Ethics and Aids in Africa. The challenge to our thinking. South Africa, Claremont.

[39] Visser, M. J (2005) "Life skills training as HIV/AIDS preventive strategy in Secondary Schools. Evaluation on a large-scale implementation process. Department of psychology. University of Pretoria. Brooklyn. Journal of social aspects of HIV/AIDS, Volume 2 (1), $203-216$.

[40] Women Action for Development, University of Namibia, \& NPS (2006) Understanding the perpetrators of violence crimes against women and girls in Namibia. Implications for prevention and treatment. University of Namibia, Windhoek

[41] Weissman, A. Cocker, J. Sherburne, L. Powers, M. B. Lovich, R. \& Mukaka, M (2006) Cross-generational relationships. Using a Continuum of Volition in HIV prevention work among young people. Gender \& development Vol. $14 \quad$ (1). http://dx.doi.org/10.1080/13552070500518293. 